\title{
Baseline Postirradiation Examination of Fuel Rodlets from the AFC-2C Experiment*
}

Fuel Cycle Research \& Development Advanced Fuels Campaign

Jason M. Harp

Heather J.M. Chichester

*Note that this document is prepared from materials presented in INL/LTD-12-26154

Prepared for GenIV SFR-AF PMB

July 2017 


\section{DISCLAIMER}

This information was prepared as an account of work sponsored by an agency of the U.S. Government. Neither the U.S. Government nor any agency thereof, nor any of their employees, makes any warranty,

expressed or implied, or assumes any legal liability or responsibility for the accuracy, completeness, or usefulness, of any information, apparatus, product, or process disclosed, or represents that its use would not infringe privately owned rights. References herein to any specific commercial product, process, or service by trade name, trade mark, manufacturer, or otherwise, does not necessarily constitute or imply its endorsement, recommendation, or favoring by the U.S. Government or any agency thereof. The views and opinions of authors expressed herein do not necessarily state or reflect those of the U.S. Government or any agency thereof. 
INL/MIS-17-42678

Revision 0

\title{
Baseline Postirradiation Examination of Fuel Rodlets from the AFC-2C, Experiment
}

\author{
Jason M. Harp \\ Heather J.M. Chichester \\ July 2017 \\ Idaho National Laboratory \\ Idaho Falls, Idaho 83415
}

http://www.inl.gov

Prepared for

GenIV SFR-AF PMB 
This Page Intentionally Blank 


\section{CONTENTS}

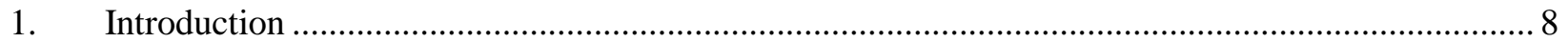

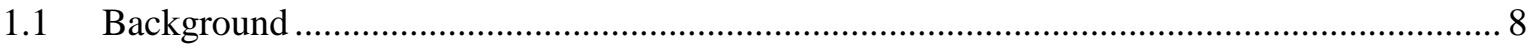

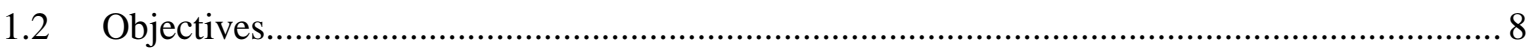

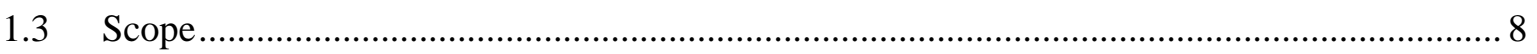

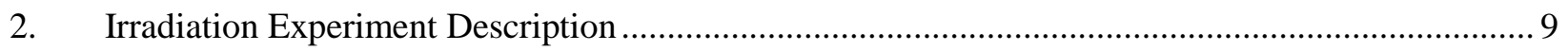

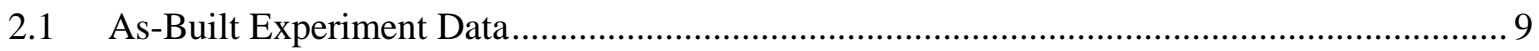

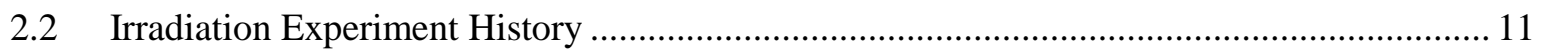

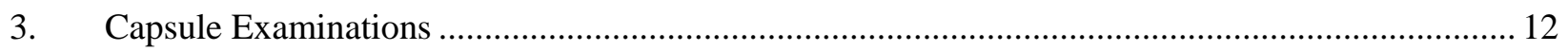

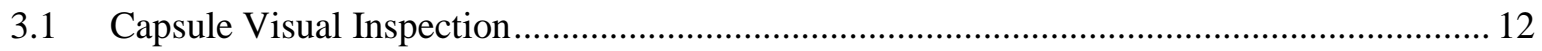

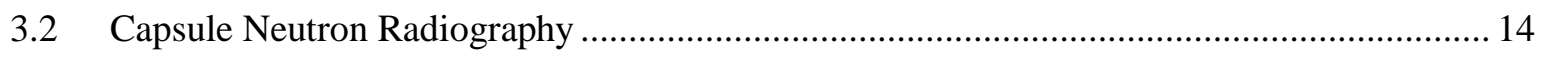

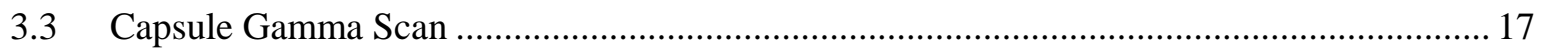

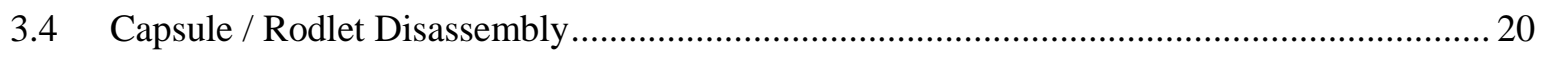

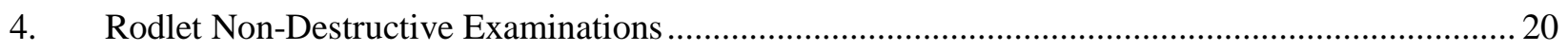

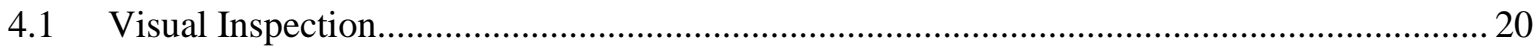

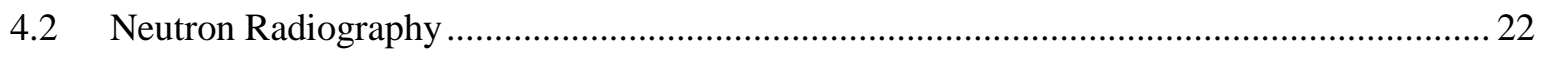

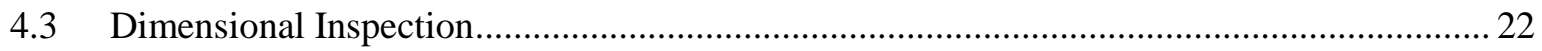

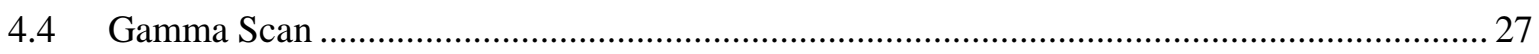

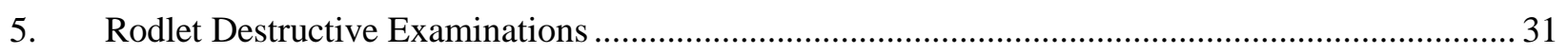

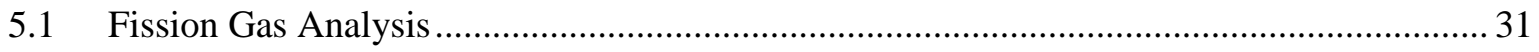

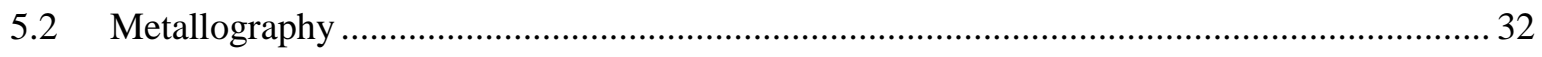

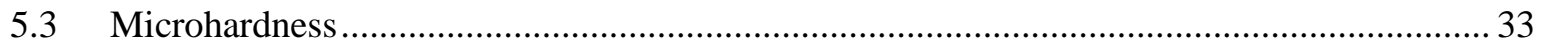

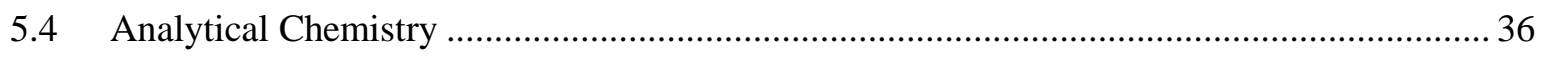

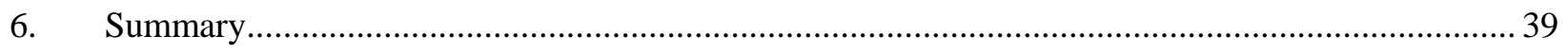

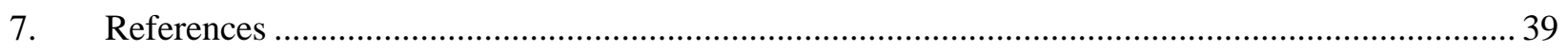




\section{FIGURES}

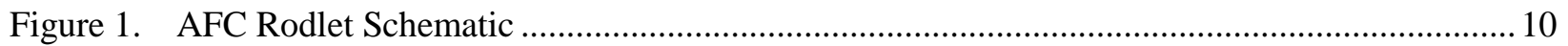

Figure 2. AFC-2C Capsule Visual Photographs (overlapping images) .................................................. 13

Figure 3. Neutron Radiography System Layout at HFEF ............................................................... 15

Figure 4. Capsule Neutron Radiography (AFC-2B on left, AFC-2C on right) (note: rodlet 1

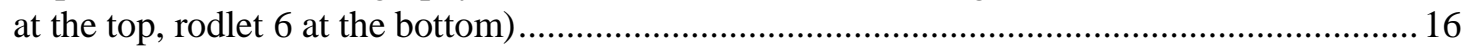

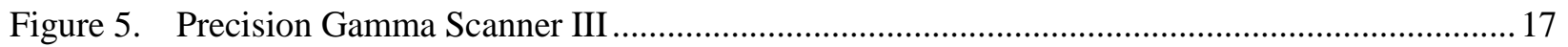

Figure 6. Gross Gamma Scan of Capsule AFC-2C............................................................................ 19

Figure 7. Isotopic Gamma Scan of Capsule AFC-2C …............................................................................ 19

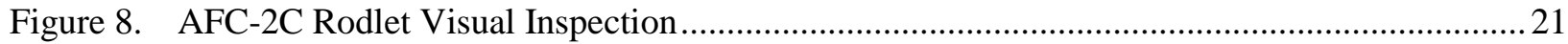

Figure 9. AFC-2C Rodlet Neutron Radiography (left to right: rodlets 1-6) .......................................22

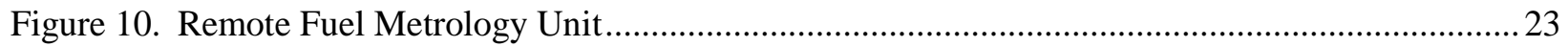

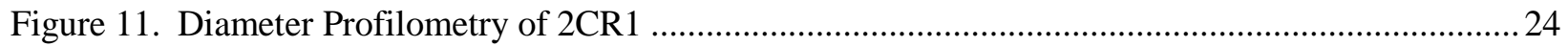

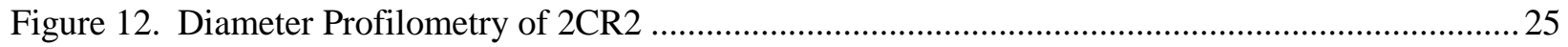

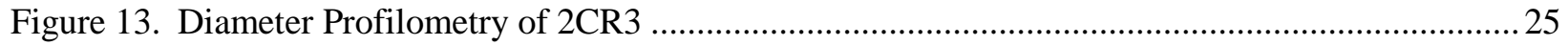

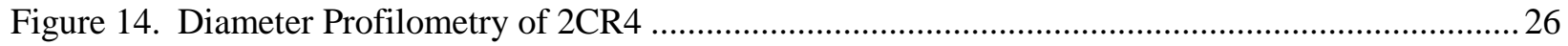

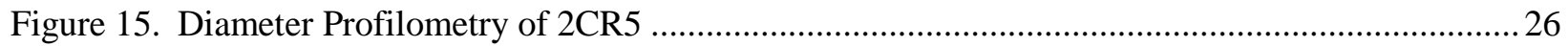

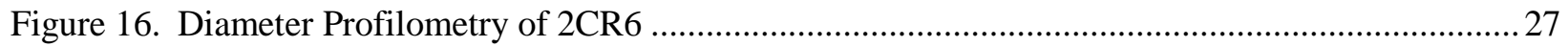

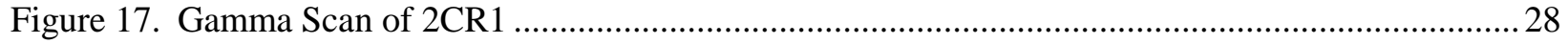

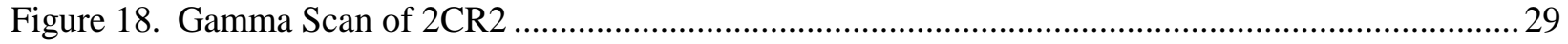

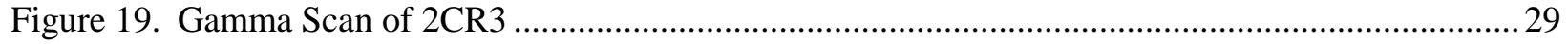

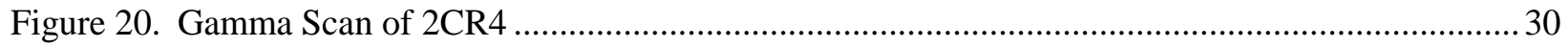

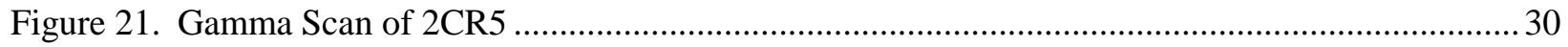

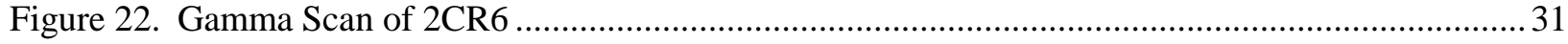

Figure 23. AFC-2C Optical Microscopy (images recorded at 50X magnification) ..................................33

Figure 24. AFC-2C Select Microhardness Testing Locations …............................................................. 35

\section{TABLES}

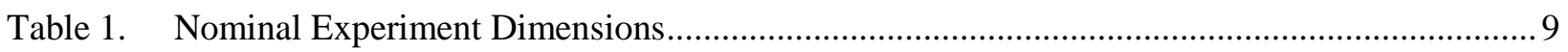

Table 2. AFC-2C Capsule As-Fabricated Experiment Data ............................................................ 11

Table 3. AFC-2C Irradiation Experiment Neutronics As-run Data................................................... 11

Table 4. Capsule Neutron Radiography Test Parameters ................................................................. 14

Table 5. Capsule Gamma Scan Test Parameters ............................................................................... 17

Table 6. Rodlet Neutron Radiography Test Parameters. ....................................................................22

Table 7. As-built Rodlet Diameter Measurements .............................................................................2 
Table 8. Rodlet Diameter Measurement Test Parameters ...............................................................23

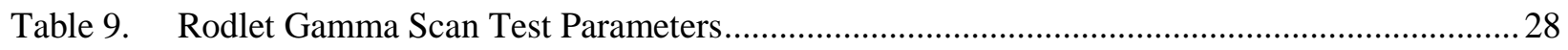

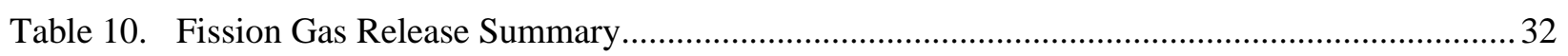

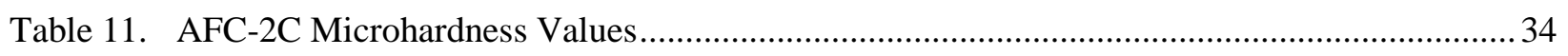

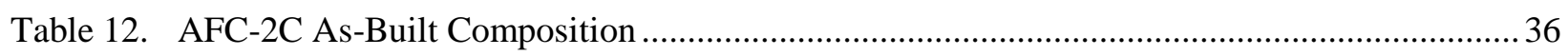

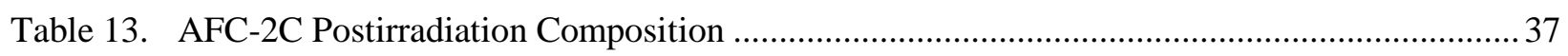

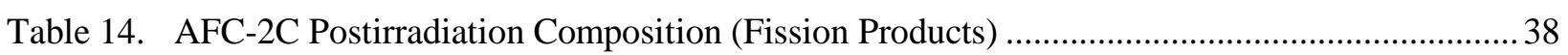

Table 15. AFC-2C Measured and Calculated (As-run) ${ }^{235} \mathrm{U}+{ }^{239} \mathrm{Pu}$ and ${ }^{241} \mathrm{Am}$ Depletions ...................... 39 


\section{ACRONYMS}

AFC

$\mathrm{AL}$

ATR

EBR-II

EFPD

FCCI

FCRD

GASR

HFEF

$\mathrm{HM}$

ICP-AES

ICP-MS

INL

LHGR

MCA

MFC

MOX

NA

NIST

NRAD

PGS

PIE

PNNL

RE

TIMS

Advanced Fuel Cycle

Analytical Laboratory

Advanced Test Reactor

Experimental Breeder Reactor II

Effective Full Power Days

Fuel-Cladding Chemical Interaction

Fuel Cycle Research \& Development

Gas Assay, Sample, and Recharge (System)

Hot Fuel Examination Facility

Heavy Metal

Inductively Coupled Atomic Emission Spectrometry

Inductively Coupled Plasma Mass Spectrometry

Idaho National Laboratory

Linear Heat Generation Rate

Multichannel Analyzer

Materials \& Fuels Complex

Mixed Oxide $\left[(\mathrm{U}, \mathrm{Pu}) \mathrm{O}_{2}\right]$

Not Applicable

National Institute for Standards and Technology

Neutron Radiography Reactor

Precision Gamma Scanner

Postirradiation Examination

Pacific Northwest National Laboratory

Rare Earth

Thermal Ionization Mass Spectrometry 


\section{Baseline Postirradiation Examination of Fuel Rodlets from the AFC-2C Experiment}

\section{INTRODUCTION}

Baseline postirradiation examination (PIE) has been conducted on transmutation fuel irradiation test AFC-2C. PIE included visual inspection, dimensional inspection, gamma scan, neutron radiography, fission gas analysis, metallography, microhardness testing, and analytical chemistry of several different fuel rodlets.

\section{$1.1 \quad$ Background}

The U. S. Fuel Cycle Research and Development (FCRD) Program seeks to develop and understand the technologies needed to transmute the long-lived transuranic actinide isotopes contained in spent nuclear fuel into shorter-lived fission products, thereby dramatically decreasing the volume of material requiring disposition and the long-term radiotoxicity and heat load of high-level waste sent to a geologic repository. The AFC-1 and AFC-2 irradiation tests are designed to evaluate the feasibility and provide fuel specimens for scientific investigations of the use of actinide-bearing fuel forms in advanced sodiumcooled fast reactors for the transmutation of transuranic elements from nuclear waste. ${ }^{1} \mathrm{AFC}-1 \mathrm{~B}, \mathrm{AFC}-$ $1 \nRightarrow$, and AFC-1F were the first set of irradiation tests that were studied, followed by their higher burnup sibling tests, AFC-1D, AFC-1G, and AFC- $1 \mathrm{H}^{2,3,4,5}$ AFC-1B and -1D contained non-fertile actinidebearing metallic alloy fuel compositions. $\mathrm{AFC}-1 \nRightarrow$ and $-1 \mathrm{G}$ primarily contained actinide-bearing nitride fuel compositions. AFC-1F and $-1 \mathrm{H}$ contained low-fertile (uranium) actinide-bearing metallic alloy fuel compositions. AFC-2A and $-2 \mathrm{~B}$ contained uranium-based, actinide-bearing metallic alloy fuels, with rare earth additions to simulate carry-over during used fuel processing. AFC-2C and -2D contained mixed oxide (MOX) fuels both with and without minor actinides.

This report describes the baseline PIE results of the AFC-2C experiment. The experiments were irradiated in the Idaho National Laboratory (INL) Advanced Test Reactor (ATR) to a peak burnup of approximately 5-8 at.\% HM for AFC-2C.

\subsection{Objectives}

The primary purpose of PIE is to characterize the relative performance of oxide fuel forms for actinide transmutation advanced fuel cycles, provide scientific characterization data to support modeling and simulation development, and to allow an initial estimate of the feasibility of various fuel designs being tested.

The objectives of PIE are to assess the condition of the experiment assembly after irradiation, prepare for rodlet unloading based on observations, and investigate the macroscopic and microscope behavior of the experimental fuels. Detailed objectives of the PIE campaign are reported in the Postirradiation Examination Plan. ${ }^{6}$

\subsection{Scope}

The work was performed at the INL Materials and Fuels Complex (MFC) Hot Fuel Examination Facility (HFEF), Neutron Radiography Reactor (NRAD), and Analytical Laboratory (AL). 


\section{IRRADIATION EXPERIMENT DESCRIPTION}

\subsection{As-Built Experiment Data}

The experimental rodlet is designed as a miniature fast reactor fuel rod with standard diameter and reduced length. The rodlet consists of a fuel column, helium bond, inert gas plenum, and stainless steel Type 421 (HT-9) cladding. A Type 316L stainless steel capsule contains a vertical stack of six rodlets. The capsule and rodlet dimensions are described in previous publications and are summarized in Table $1 .^{7,8}$ The annular gap between the oxide fuel column and rodlet inner diameter is initially filled with helium. The annular gap between the rodlet outer diameter and capsule inner diameter is filled with helium and designed to provide the thermal resistance necessary to achieve the design irradiation temperature of the fuel specimen.

Table 1. Nominal Experiment Dimensions

\begin{tabular}{|c|c|c|}
\hline \multicolumn{2}{|r|}{ Design Parameter } & \\
\hline \multirow{6}{*}{$\begin{array}{l}\frac{0}{J} \\
\underset{\tilde{U}}{\tilde{U}}\end{array}$} & Material & 316L SS \\
\hline & Height (in. / cm) & $52.0(132.1)$ \\
\hline & Outer Diameter (in. / cm) & $0.354(0.899)$ \\
\hline & Inner Diameter (in. / cm) & $0.234(0.594)$ \\
\hline & Wall thickness (in. / cm) & $0.060(0.152)$ \\
\hline & Inert Gas Fill & Helium \\
\hline \multirow{6}{*}{$\begin{array}{l}\vec{e} \\
\vec{\nabla} \\
\stackrel{0}{\alpha}\end{array}$} & Material & 421SS (HT9) \\
\hline & Height (in. / cm) & $6.0(15.2)$ \\
\hline & Outer Diameter (in. / cm) & $0.230(0.584)$ \\
\hline & Inner Diameter (in. / cm) & $0.194(0.493)$ \\
\hline & Wall Thickness (in. / cm) & $0.018(0.046)$ \\
\hline & Inert Gas Fill & Helium \\
\hline \multirow{7}{*}{ 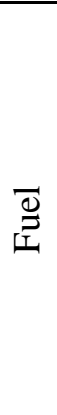 } & Type & Oxide \\
\hline & Bond Material & Helium \\
\hline & Smear Density (\%) & $84-91$ \\
\hline & Porosity (\%) & $7-14$ \\
\hline & Outer Diameter (in. / cm) & $0.192(0.488)$ \\
\hline & Active Fuel Stack Height (in. / cm) & $1.50(3.81)$ \\
\hline & $\begin{array}{l}\text { Total Fuel Column Height (in. / cm) } \\
\text { (includes Insulator Pellets) }\end{array}$ & $2.00(5.08)$ \\
\hline
\end{tabular}

The oxide fuel column consists of six fuel pellets with a nominal height of $0.25 \mathrm{in} .(0.64 \mathrm{~cm})$ each with an additional insulator pellet (depleted $\mathrm{UO}_{2}$ ) at both the top and bottom of the fuel stack for a total column height of $2.0 \mathrm{in} .(5.08 \mathrm{~cm})$. Oxide rodlets contain a hold-down spring above the fuel to ensure that the fuel column does not move during transportation and handling. Figure 1 shows a schematic of the metallic and oxide fuel rodlets. 


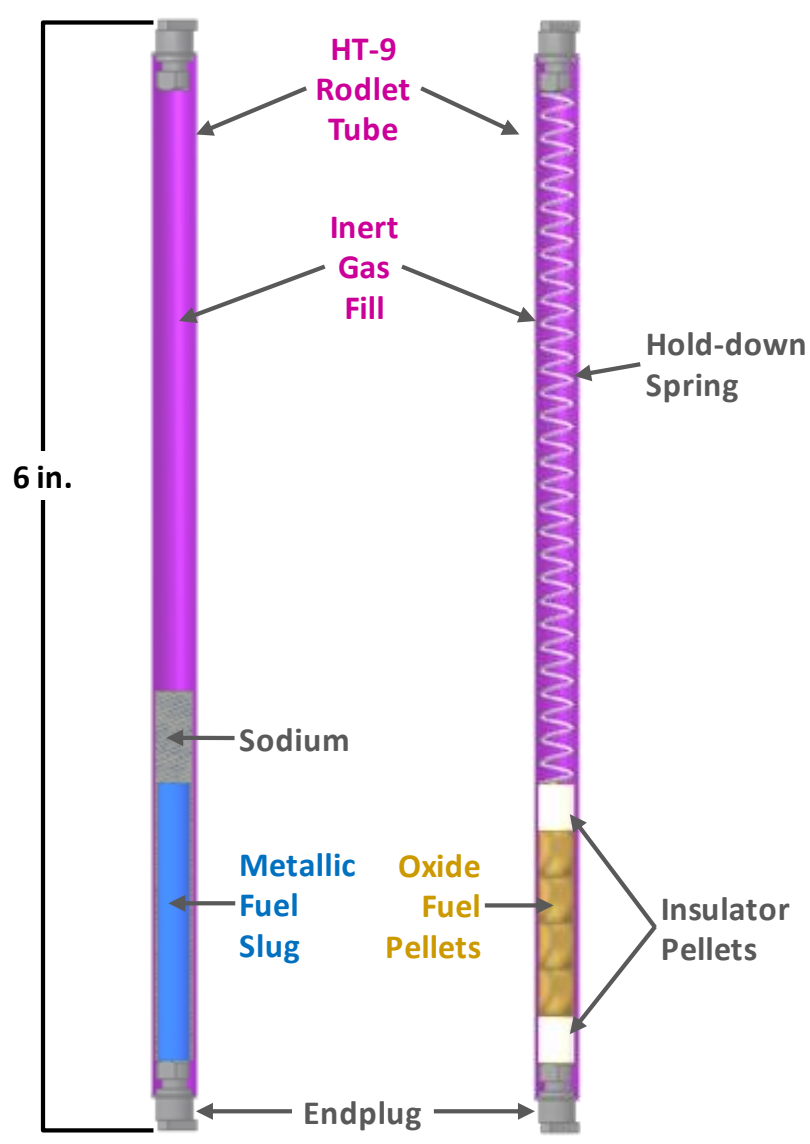

Figure 1. AFC Rodlet Schematic

The irradiation test assembly consists of the experiment basket and one capsule, which contains six rodlets. The experiment basket is designed to interface the capsule with the ATR and to act as a thermal neutron flux filter with the use of cadmium. The capsules and rodlets are designated by unique serial numbers. As-fabricated experiment parameters are summarized in Table 2. 
Table 2. AFC-2C Capsule As-Fabricated Experiment Data

\begin{tabular}{|c|c|c|c|c|c|c|}
\hline Capsule Position & 2CR1 & $2 \mathrm{CR} 2$ & 2CR3 & $2 \mathrm{CR} 4$ & 2CR5 & 2CR6 \\
\hline Rodlet Identification & $\mathrm{AFC} 2 \mathrm{C}-\mathrm{R} 1$ & AFC2C-R2 & $\mathrm{AFC} 2 \mathrm{C}-\mathrm{R} 3$ & $\mathrm{AFC} 2 \mathrm{C}-\mathrm{R} 4$ & AFC2C-R5 & AFC2C-R6 \\
\hline Rodlet Length & 6.000 & 6.000 & 5.999 & 5.997 & 6.000 & 5.999 \\
\hline Rodlet OD & 0.2294 & 0.2293 & 0.2294 & 0.2294 & 0.2293 & 0.2293 \\
\hline Rodlet Mass (calc) & 20.99 & 20.43 & 21.04 & 20.49 & 21.03 & 21.04 \\
\hline Active Fuel Length (in.) & 1.497 & 1.335 & 1.496 & 1.335 & 1.504 & 1.497 \\
\hline Average Fuel OD & 0.1920 & 0.1910 & 0.1918 & 0.1915 & 0.1918 & 0.1917 \\
\hline Fuel Mass & 6.852 & 6.184 & 6.864 & 6.228 & 6.875 & 6.846 \\
\hline Average Fuel Density $\left(\mathrm{g} / \mathrm{cm}^{3}\right)$ & 9.654 & 9.855 & 9.699 & 9.886 & 9.620 & 9.657 \\
\hline Fuel Nominal Composition & $\begin{array}{c}\left(\mathrm{U}_{0.75}, \mathrm{Pu}_{0.20}\right. \\
\left.\mathrm{Am}_{0.03} \mathrm{~Np}_{0.02}\right) \\
\mathrm{O}_{1.95} \\
\end{array}$ & $\begin{array}{c}\left(\mathrm{U}_{0.80}, \mathrm{Pu}_{0.20}\right) \\
\mathrm{O}_{1.98}\end{array}$ & $\begin{array}{c}\left(\mathrm{U}_{0.75}, \mathrm{Pu}_{0.20}\right. \\
\mathrm{Am}_{\left.0.03, \mathrm{~Np}_{0.02}\right)} \\
\mathrm{O}_{1.98} \\
\end{array}$ & $\begin{array}{c}\left(\mathrm{U}_{0.80}, \mathrm{Pu}_{0.20}\right) \\
\mathrm{O}_{1.98}\end{array}$ & $\begin{array}{c}\left(\mathrm{U}_{0.75}, \mathrm{Pu}_{0.20}\right. \\
\left.\mathrm{Am}_{0.03}, \mathrm{~Np}_{0.02}\right) \\
\mathrm{O}_{1.95} \\
\end{array}$ & $\begin{array}{c}\left(\mathrm{U}_{0.75}, \mathrm{Pu}_{0.20},\right. \\
\left.\mathrm{Am}_{0.03,} \mathrm{~Np}_{0.02}\right) \\
\mathrm{O}_{1.98} \\
\end{array}$ \\
\hline$(\mathrm{wt} \%)$ & 66.56 & 70.6 & 66.56 & 70.6 & 66.56 & 66.56 \\
\hline$(\%)$ & 44.558 & 42.125 & 44.558 & 42.125 & 44.558 & 44.558 \\
\hline${ }^{235} \mathrm{U}$ & 54.818 & 57.286 & 54.818 & 57.286 & 54.818 & 54.818 \\
\hline$(w t \%)$ & 16.99 & 17.01 & 16.99 & 17.01 & 16.99 & 16.99 \\
\hline${ }^{239} \mathrm{Pu}$ & 94.600 & 94.703 & 94.600 & 94.703 & 94.600 & 94.600 \\
\hline$(w t \%)$ & 2.36 & 0.1246 & 2.36 & 0.1246 & 2.36 & 2.36 \\
\hline$(w t \%)$ & 1.28 & NA & 1.28 & NA & 1.28 & 1.28 \\
\hline $\mathrm{O} / \mathrm{M}$ & 1.962 & 1.982 & 1.986 & 1.982 & 1.962 & 1.986 \\
\hline Rodlet Fill Gas & & & & & & \\
\hline$(\mathrm{mole} \%)$ & 99.6 & 99.6 & 99.6 & 99.6 & 99.6 & 99.6 \\
\hline (ppm) & 7.5 & 7.5 & 7.6 & 7.0 & 7.0 & 7.0 \\
\hline Capsule Fill Gas & \multicolumn{6}{|c|}{,$<0.4 \mathrm{~N}_{2}$} \\
\hline Capsule Mass & \multicolumn{6}{|c|}{509.5} \\
\hline
\end{tabular}

NA: Not Applicable

\subsection{Irradiation Experiment History}

The as-run time-averaged linear heat generation rate (LHGR) and burnup of the AFC-2C irradiation experiment is summarized in Table $3 .^{9,10,11,12,13,14,15,16,17,18}$

Table 3. AFC-2C Irradiation Experiment Neutronics As-run Data

\begin{tabular}{|c|c|c|c|c|c|}
\hline \multirow{3}{*}{ Rodlet } & \multirow{3}{*}{$\begin{array}{c}\text { AFC-2C } \\
\text { Nominal Composition } \dagger\end{array}$} & \multicolumn{4}{|c|}{$\begin{array}{c}\text { AFC-2C } \\
\text { EOC } 145 B\end{array}$} \\
\hline & & \multirow{2}{*}{$\begin{array}{c}\text { Average } \\
\text { LHGR } \\
(\mathrm{W} / \mathrm{cm})\end{array}$} & \multirow{2}{*}{$\begin{array}{l}\text { Fission } \\
\text { Density } \\
\left(\mathrm{f} / \mathrm{cm}^{3}\right)\end{array}$} & \multicolumn{2}{|c|}{ Burnup (at.\%) } \\
\hline & & & & $\begin{array}{l}{ }^{235} \mathrm{U}+ \\
{ }^{239} \mathrm{Pu}\end{array}$ & HM \\
\hline 1 & $\left(\mathrm{U}_{0.75}, \mathrm{Pu}_{0.20}, \mathrm{Am}_{0.03}, \mathrm{~Np}_{0.02}\right) \mathrm{O}_{1.95}$ & 219 & $9.19 \mathrm{E} 20$ & 10.37 & 5.79 \\
\hline 2 & $\left(\mathrm{U}_{0.80}, \mathrm{Pu}_{0.20}\right) \mathrm{O}_{1.98}$ & 298 & $1.25 \mathrm{E} 21$ & 13.78 & 7.11 \\
\hline 3 & $\left(\mathrm{U}_{0.75}, \mathrm{Pu}_{0.20}, \mathrm{Am}_{0.03}, \mathrm{~Np}_{0.02}\right) \mathrm{O}_{1.98}$ & 321 & $1.35 \mathrm{E} 21$ & 15.03 & 8.36 \\
\hline 4 & $\left(\mathrm{U}_{0.80}, \mathrm{Pu}_{0.20}\right) \mathrm{O}_{1.98}$ & 336 & $1.41 \mathrm{E} 21$ & 15.38 & 7.94 \\
\hline 5 & $\left(\mathrm{U}_{0.75}, \mathrm{Pu}_{0.20}, \mathrm{Am}_{0.03}, \mathrm{~Np}_{0.02}\right) \mathrm{O}_{1.95}$ & 300 & $1.25 \mathrm{E} 21$ & 14.06 & 7.86 \\
\hline 6 & $\left(\mathrm{U}_{0.75}, \mathrm{Pu}_{0.20}, \mathrm{Am}_{0.03}, \mathrm{~Np}_{0.02}\right) \mathrm{O}_{1.98}$ & 243 & $1.02 \mathrm{E} 21$ & 11.51 & 6.40 \\
\hline
\end{tabular}

AFC-2C inserted cycle 143A, 24 Sep 2008; discharged cycle 145B, 24 Jan 2010; 261.9 EFPD

$\dagger$ Alloy composition expressed in mole percent 


\section{CAPSULE EXAMINATIONS}

\subsection{Capsule Visual Inspection}

Visual inspection by through-window digital still photography was performed using a Nikon D200 10.2 megapixel digital camera with 80-400 mm lens at HFEF Window 14M. Overlapping photographs were recorded at a single viewing angle for each capsule. The upper and lower welds appear intact and heat zones corresponding to fuel region elevations are clearly seen. There are no obvious visible defects. Figure 2 show photographs of the capsule visual inspection. 


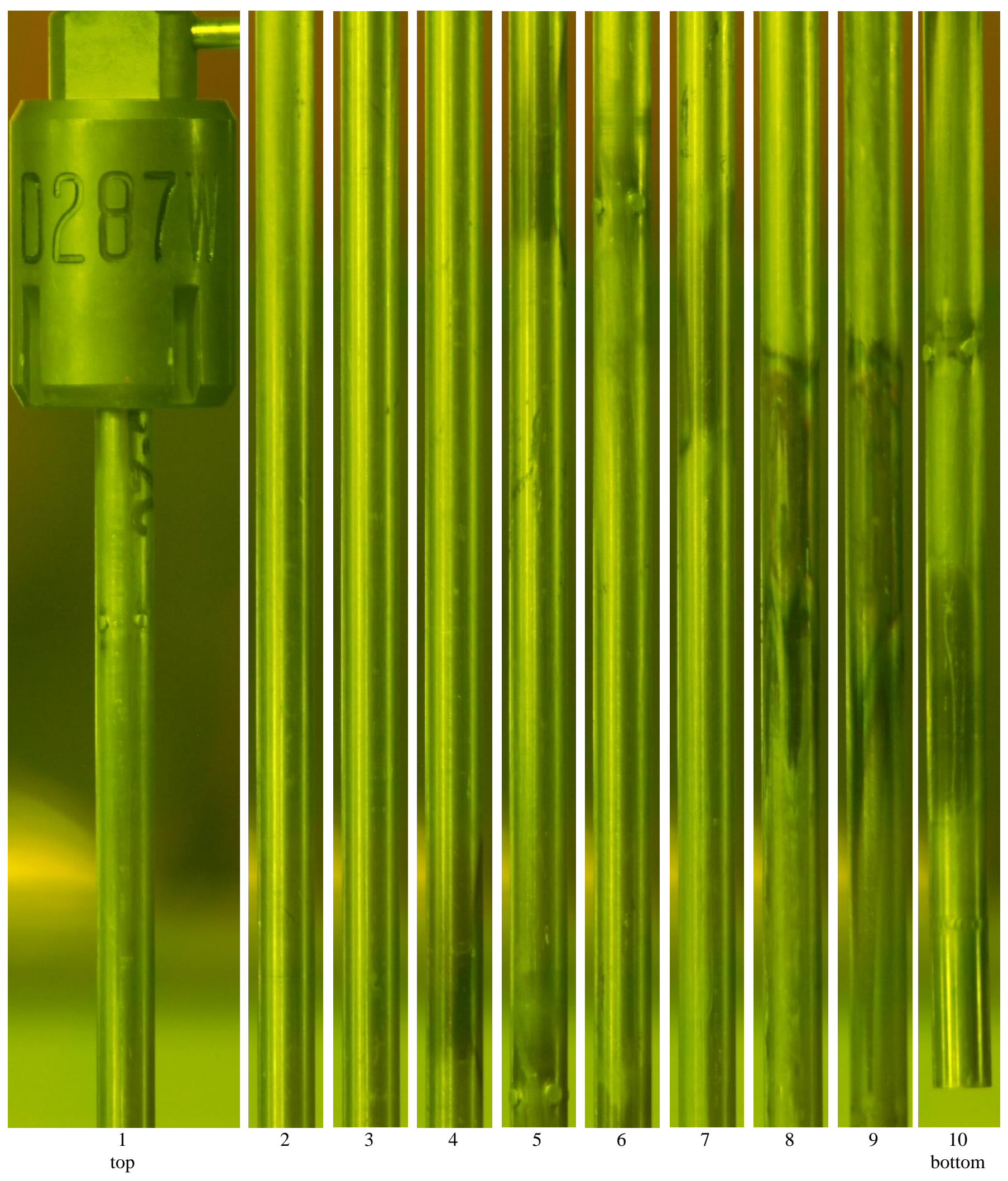

Figure 2. AFC-2C Capsule Visual Photographs (overlapping images) 


\subsection{Capsule Neutron Radiography}

Neutron radiography was performed with the NRAD facility (east radiography station) which interfaces to HFEF at Window 4M. Figure 3 shows the layout of the neutron radiography system at HFEF. Test parameters are detailed in Table 4.

Neutron radiography was provided for capsules AFC-2B and AFC-2C at a single azimuthal orientation. Both capsules were imaged at the same time. Neutron radiography of each capsule consists of a series of images that span the full length. Each image spans approximately 17 in. $(43 \mathrm{~cm})$. Adjacent images have approximately 3-6 in. (7-15 cm) overlap. The axial position is determined from a gadolinium-treated scale (marking spacing 0.025 in.) incorporated in the NRAD fixture.

Neutron radiography was performed by indirect radiography. The neutron attenuated image of a specimen is first imaged on dysprosium (Dy) and indium (In) activation foils, that then are processed with radiation sensitive media (i.e., photographic film). The radioactive decay of the Dy and In foils exposes the media resulting in the neutron radiograph. Digital images are developed from high resolution (600 lpi) digital scans of the photographic negatives. In-cell radiography equipment at Window 4M lowers specimens below the HFEF main-cell floor level into the NRAD beam elevation for radiography.

Test shots were performed before neutron radiography to verify system operation and to ensure that test parameters result in acceptable image quality. The quality of the final images is validated by a certified neutron radiographer and system engineer and documented on the Neutron Radiography Validation Checklist.

Table 4. Capsule Neutron Radiography Test Parameters

\begin{tabular}{|c|c|c|c|c|c|c|}
\hline Specimen & Z-Range & $\begin{array}{c}\text { Azimuthal } \\
\text { Orientation }\end{array}$ & $\begin{array}{c}\text { Activation } \\
\text { Foils }\end{array}$ & Z-Step & $\begin{array}{c}\text { Exposure Times } \\
\text { Foil / Media } \uparrow\end{array}$ & $\begin{array}{c}\text { Digital } \\
\text { Scan LPI }\end{array}$ \\
\hline $\begin{array}{c}\text { AFC-2B } \\
\text { AFC-2C }\end{array}$ & Full length & One scan & Dy / In & $\begin{array}{c}15 \mathrm{in} . \\
(38 \mathrm{~cm})\end{array}$ & $\begin{array}{c}22 \mathrm{~min} / \sim 24 \mathrm{hr} \text { D3SC } \\
22 \mathrm{~min} / \sim 24 \mathrm{hr} T\end{array}$ & 600 \\
\hline
\end{tabular}

$\dagger$ Media types included D3SC film for Dy foils, T film for In foils. Additional media types used for historic comparison and advanced development include SR1 single-sided film, DR1 double-sided film and imaging panel for both Dy/In foils. 


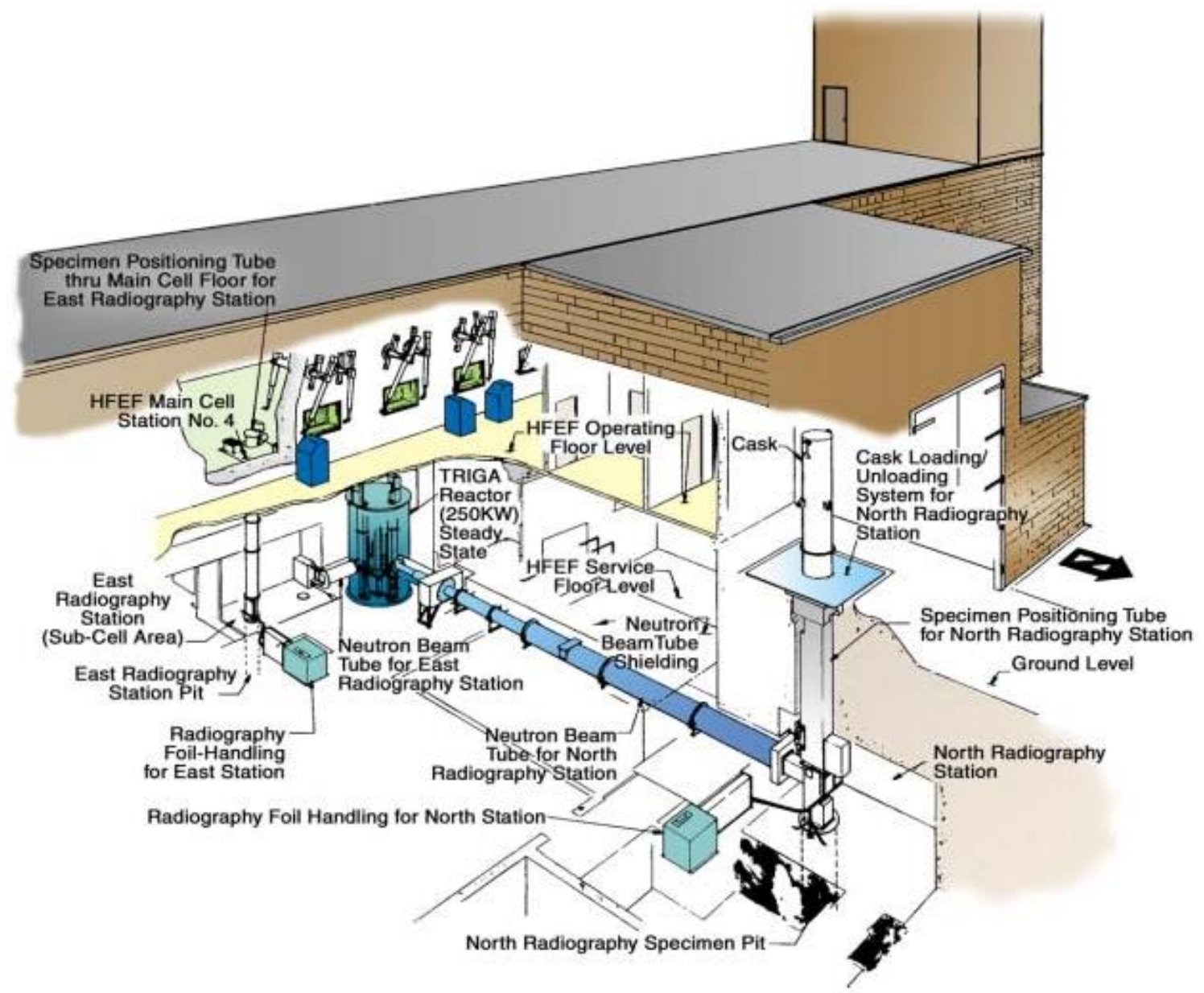

Figure 3. Neutron Radiography System Layout at HFEF

Figure 4 shows the neutron radiographs of capsules AFC-2B and AFC-2C at four elevations to capture to full capsule length. All of the rodlets in AFC-2B appear to have fuel around the lower rodlet endplugs, suggesting localized liquid phase formation occurred during irradiation (a similar finding to the sister experiment AFC-2A). ${ }^{5}$ The appearance of AFC-2C reveals no unusual behavior. 

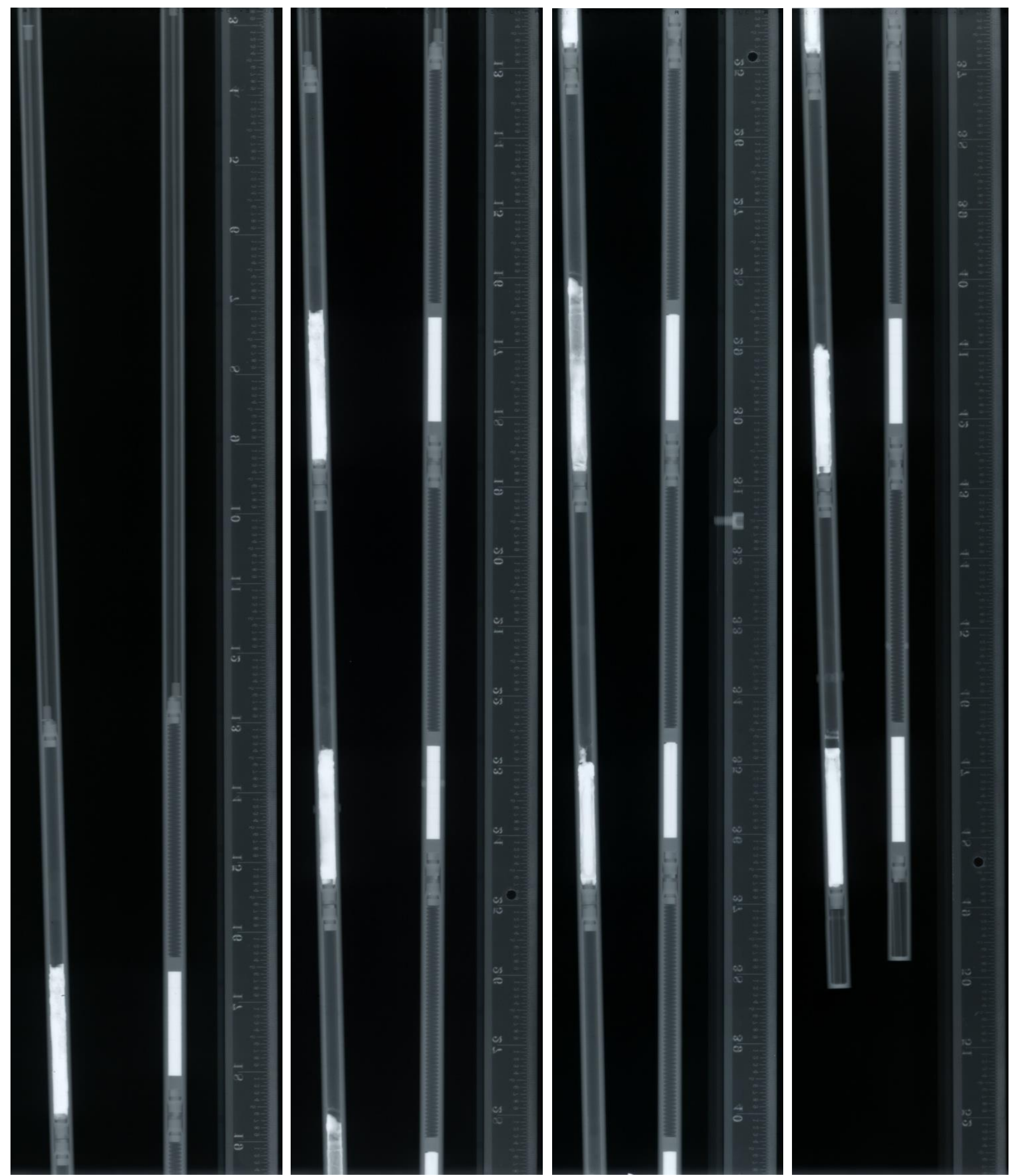

top

Figure 4. Capsule Neutron Radiography (AFC-2B on left, AFC-2C on right) (note: rodlet 1 at the top, rodlet 6 at the bottom) 


\subsection{Capsule Gamma Scan}

The capsule gamma scan was performed with the Precision Gamma Scanner (PGS)-III at HFEF Window 7M. Figure 5 shows a schematic of the PGS-III System. The test parameters are detailed in Table 5.

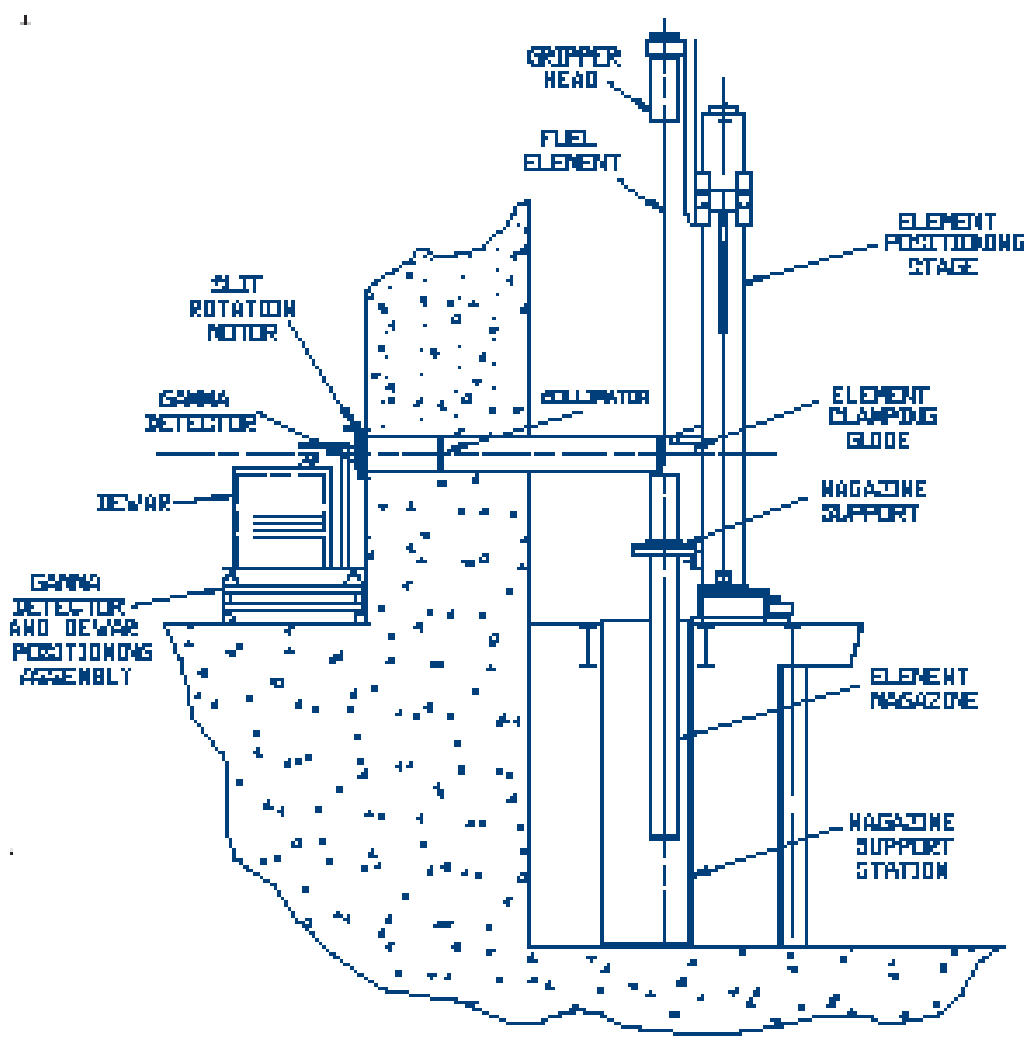

Figure 5. Precision Gamma Scanner III

Table 5. Capsule Gamma Scan Test Parameters

\begin{tabular}{|c|c|c|ll|c|}
\hline Specimen & $\begin{array}{c}\text { Z-Range } \\
\text { (wrt Top) }\end{array}$ & $\begin{array}{c}\text { Scan } \\
\text { Time }\end{array}$ & \multicolumn{1}{|c|}{ Spectra Analysis } & $\begin{array}{c}\text { Z-step Interval } \\
\text { Collimator Width }\end{array}$ \\
\hline AFC-2C & $\begin{array}{c}0-\geq 40 \mathrm{in} . \\
(0-\geq 102 \mathrm{~cm})\end{array}$ & $120 \mathrm{~s}$ & $\begin{array}{l}\text { Gross } \\
\text { Isotopics }\end{array}$ & $\begin{array}{l}(\text { total }) \\
\left({ }^{54} \mathrm{Mn},{ }^{60} \mathrm{Co},{ }^{95} \mathrm{Zr},{ }^{95} \mathrm{Nb},{ }^{103} \mathrm{Ru},\right.\end{array}$ & 0.10 in. $(0.25 \mathrm{~cm})$ \\
\hline
\end{tabular}

Gamma scans were collected for AFC-2C. The gamma scans recorded gross (total) and isotopic data from 0 to $\geq 40$ in. $(102 \mathrm{~cm})$ distance from the top of the capsule, which corresponds to the column length of all six fuel rodlets, at intervals of $0.10 \mathrm{in} .(0.25 \mathrm{~cm})$. The scan time at each axial position was $120 \mathrm{sec}$ with a collimator width of 0.10 in. $(0.25 \mathrm{~cm})$. One axial scan was recorded for each capsule.

The PGS-III primary gamma-spectra detector is a high-purity germanium crystal (HPGe) surrounded by a sodium iodide (NaI) detector to correct for background due to Compton scattering. Spectral analysis is performed with a multichannel analyzer (MCA) capable of at least 8192 channels of resolution with at least 24-bit count capacity per channel. The MCA conversion time is $\leq 10$ microsecond to reduce the spectra collection time. The axial scan was obtained in one stage configuration. 
The gamma scan activity uncertainty is $\pm 1.0 \%$ to $10.0 \%$ for count rates ranging from $10 \mathrm{k}$ cps to $1 \mathrm{k}$ cps, respectively. The PGS-III accuracy is validated at the beginning and ending of a series of measurements and at the beginning and ending of each gamma scan during an extended period of use. The gammaspectra detector is validated by at least two certified radioactive source standards (e.g., Ba-133 and Cs137). The full width at half maximum resolution for $122 \mathrm{keV}$ gamma rays is $0.735 \mathrm{keV}$. The stage position uncertainty is \pm 0.003 in. $( \pm 0.076 \mathrm{~mm})$ in the $X$ and $Y$ direction, \pm 0.005 in. $( \pm 0.127 \mathrm{~mm})$ in the $\mathrm{Z}$ direction, and $\pm 0.5^{\circ}$ in azimuthal orientation.

The gamma scan spectra analysis included gross (total) and select isotopics. Figure 6 and Figure 7 show the capsule gross and isotopic gamma scans for AFC-2C.

${ }^{54} \mathrm{Mn}$ and ${ }^{60} \mathrm{Co}$ indicate activation of the capsule and rodlet tube material. The ${ }^{54} \mathrm{Mn}$ and ${ }^{60} \mathrm{Co}$ profiles will tend to follow the reactor core flux profile and will also increase in regions of increased stainless steel content (i.e., at the rodlet endplugs). ${ }^{95} \mathrm{Nb}$ and ${ }^{103} \mathrm{Ru}$ represent the fuel region. ${ }^{103} \mathrm{Ru}$ is tightly bound in the fuel structure and is a good measure of fuel density at a given axial location. If the fuel density remains axially constant then ${ }^{103} \mathrm{Ru}$ intensity can mimic the burnup profile. ${ }^{144} \mathrm{Ce}$ and ${ }^{144} \mathrm{Pr}$ represent the rare earth fission products which are known to moderately migrate from hotter to cooler parts of the fuel slug in metallic fuel. Cs isotopes $\left({ }^{134} \mathrm{Cs},{ }^{137} \mathrm{Cs}\right)$ are highly mobile in liquid or vapor phase and can dissolve in the bond sodium.

For metallic fuel, typical behavior includes migration of Cs into the sodium bond and sodium plug above the fuel column; consequently the cesium axial profile generally shows a peak near the top of the fuel column. Lack of cesium above the fuel column in rodlets 2BR4 and 2BR6 could indicate a breached rodlet during irradiation where the sodium was able to leak out of the rodlet. The $\mathrm{Nb}$ and Cs profiles in 2BR3 appear abnormal and neutron radiography (Figure 4) shows atypical fuel density, suggesting an unexpected mixture of sodium and fuel at the top of the fuel column.

No unusual behavior is observed from the gamma scans of AFC-2C. 


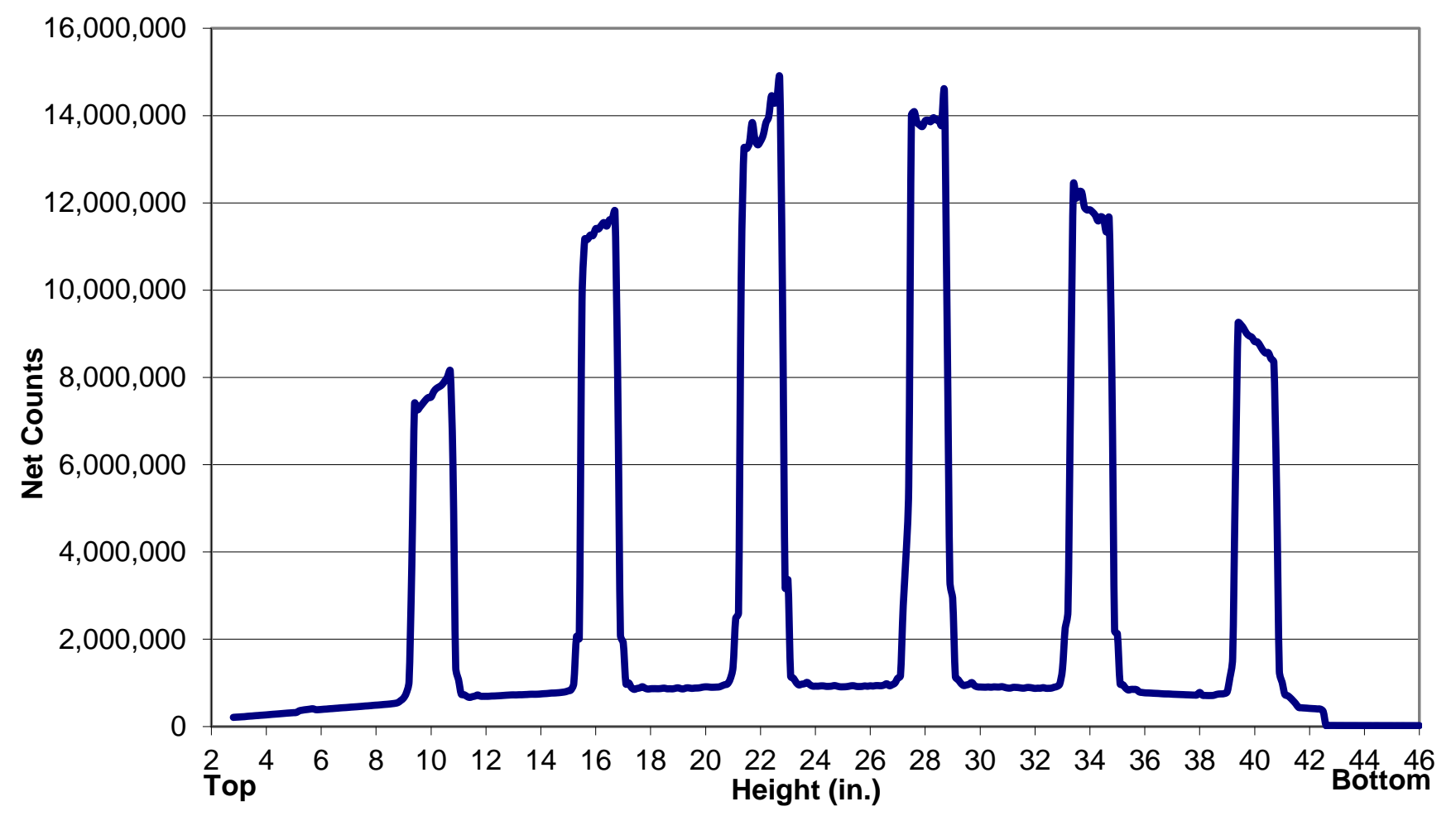

Figure 6. Gross Gamma Scan of Capsule AFC-2C

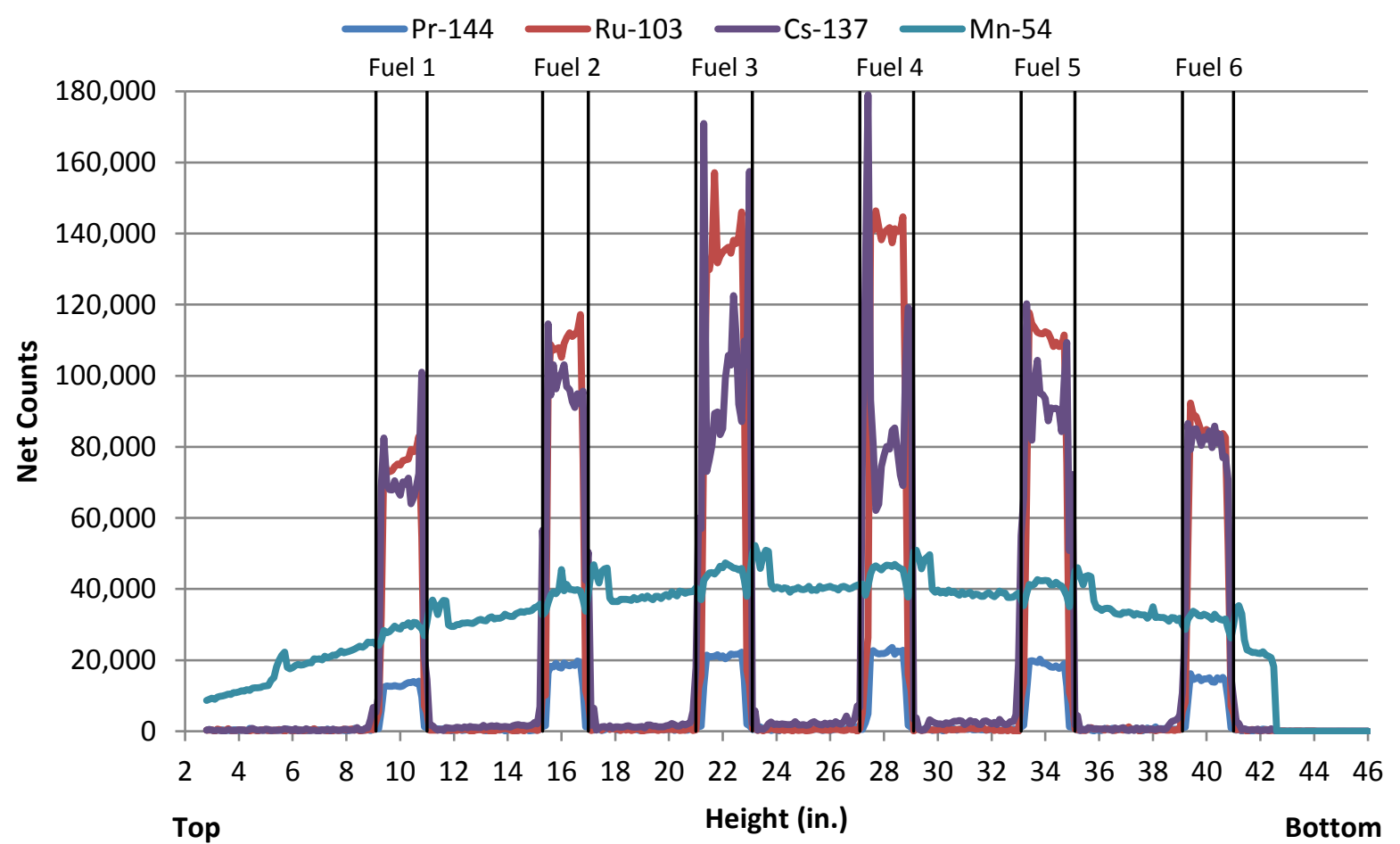

Figure 7. Isotopic Gamma Scan of Capsule AFC-2C 


\subsection{Capsule / Rodlet Disassembly}

Capsule disassembly was performed for AFC-2C with a precision table top mill and a new capsule disassembly device. Each capsule was first sectioned at the top and bottom of each rodlet (as determined by neutron radiography images).

After sectioning, each capsule/rodlet segment was milled. The capsule wall was milled away in multiple passes to remove approximately $0.040 \mathrm{in} .(0.10 \mathrm{~cm})$, then rotated $180^{\circ}$ and the opposite side was milled to removed approximately $0.040 \mathrm{in} .(0.10 \mathrm{~cm})$. The capsule/rodlet segment was placed in the capsule disassembly device with one groove situated at the bottom and the other groove situated at the top where teeth from the disassembly device fit into the groove. A pry bar is attached in the groove, between the teeth, and pulled to open the capsule wall (in an unzipping fashion

\section{RODLET NON-DESTRUCTIVE EXAMINATIONS}

\subsection{Visual Inspection}

Visual inspection by through-window digital still photography was performed using a Nikon D200 10.2 megapixel digital camera with 80-400 mm lens at HFEF Window 3M. A new stage was used for rodlet visual inspection with a calibrated scale and a shelf to hold one rodlet. Photographs were taken at 2 viewing angles, $0^{\circ}$ and $180^{\circ}$, where $0^{\circ}$ orientation is with the rodlet label facing the camera (where visible). Figure 8 shows the visual inspection photographs of AFC-2C.

The AFC-2C rodlets have no visible defects. Heat discoloration zones corresponding to the fuel region are observed. 

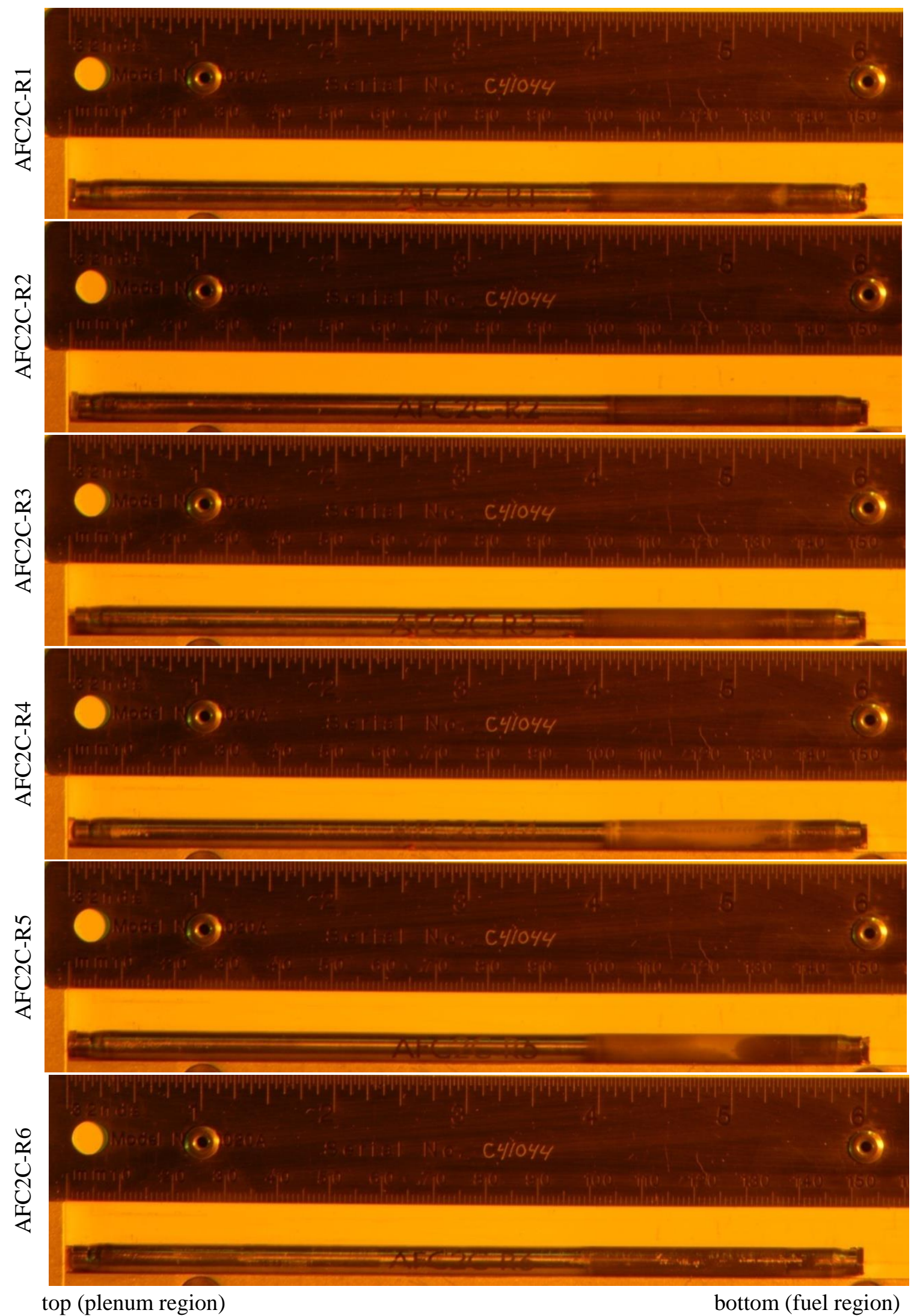

Figure 8. AFC-2C Rodlet Visual Inspection 


\subsection{Neutron Radiography}

Neutron radiography was performed with the NRAD facility which interfaces to HFEF at Window 4M. Test parameters are detailed in Table 6 . The neutron radiography method and process are described in Section 3.2. Neutron radiographs of the six fuel rodlets from AFC-2C are shown in Figure 9. AFC-2C appears to have no unusual behavior.

Table 6. Rodlet Neutron Radiography Test Parameters.

\begin{tabular}{|c|c|c|c|c|c|}
\hline Specimen & Z-Range & $\begin{array}{c}\text { Azimuthal } \\
\text { Orientation }\end{array}$ & $\begin{array}{c}\text { Activation } \\
\text { Foils }\end{array}$ & $\begin{array}{c}\text { Exposure Times } \\
\text { Foil / Media } \uparrow\end{array}$ & $\begin{array}{c}\text { Digital } \\
\text { Scan LPI }\end{array}$ \\
\hline AFC-2C & $\begin{array}{c}\text { Full } \\
\text { length }\end{array}$ & One scan & Dy / In & $\begin{array}{c}22 \mathrm{~min} / \sim 24 \mathrm{hr} \text { D3SC } \\
22 \mathrm{~min} / \sim 24 \mathrm{hr} \text { T }\end{array}$ & 600 \\
\hline
\end{tabular}

$\uparrow$ Media types included D3SC film for Dy foils, T film for In foils. Additional media types used for historic comparison and advanced development include SR1 single-sided film, DR1 double-sided film and imaging panel for both Dy/In foils.

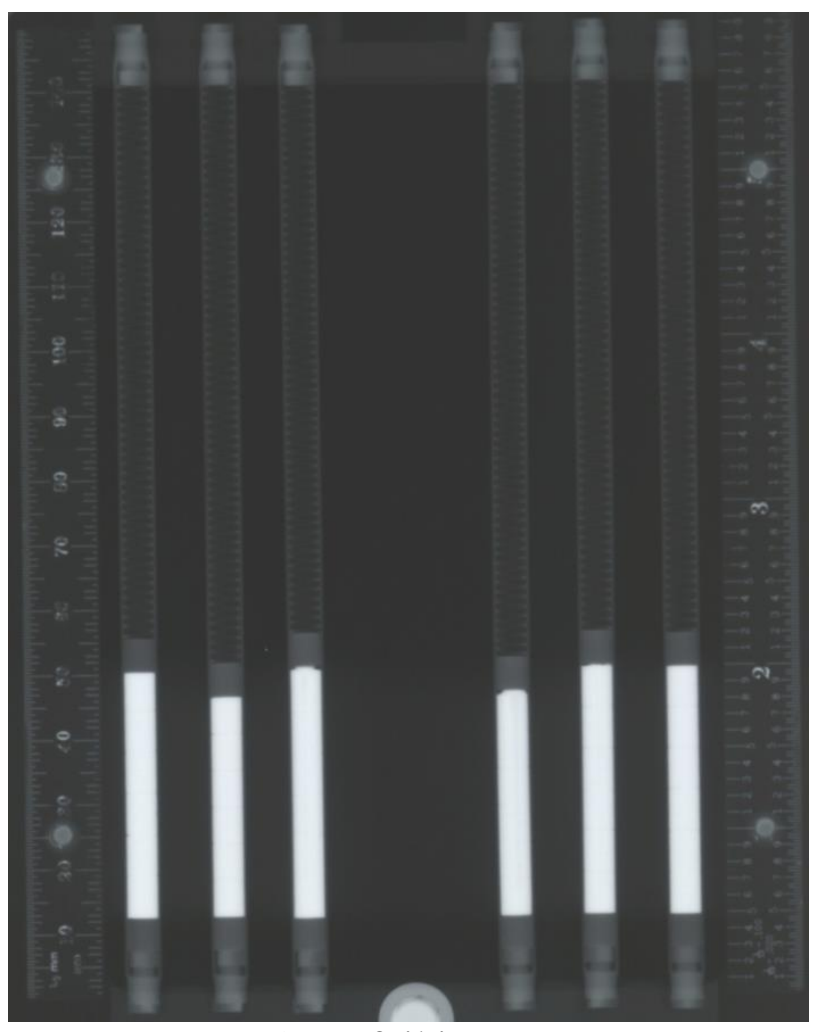

a) Dy foil image

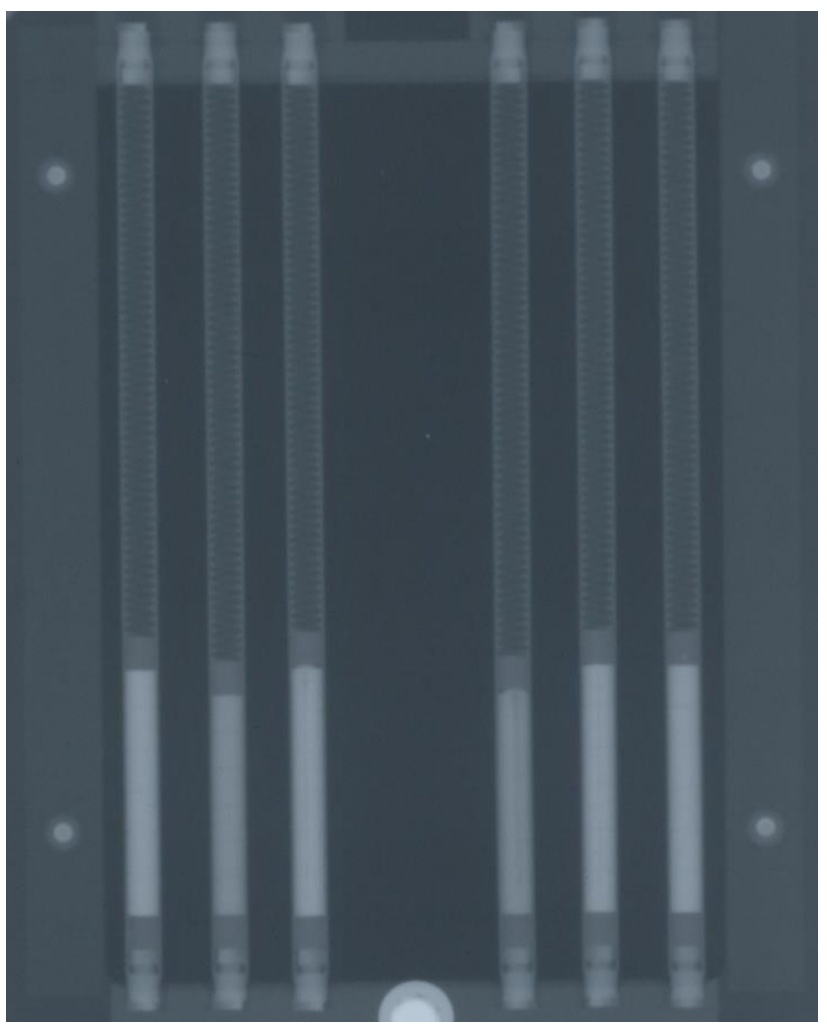

b) In foil image

Figure 9. AFC-2C Rodlet Neutron Radiography (left to right: rodlets 1-6)

\subsection{Dimensional Inspection}

The diameter profile measurement was performed with the Remote Fuel Metrology System at HFEF Window 3M. The test parameters are detailed in Table 8. All six AFC-2C rodlets were measured. 
The Remote Fuel Metrology System measures the diameter profile by contact profilometry. The diameter measurement is made by two horizontally-opposed magnetic transducers connected to sapphire-tipped contact probes. Linear positions and displacements are derived from a digital-position readout system and are recorded on a data acquisition system. The Remote Fuel Metrology System, shown in Figure 10, scans all azimuthal positions at each axial elevation step.

The diameter measurement uncertainty is $\pm 0.0003 \mathrm{in}$. $(0.0076 \mathrm{~mm})$. The diameter measurement accuracy is validated at the beginning of a series of measurements and at the beginning and ending of each shift of operation during an extended period of use. This calibration check is performed using two certified plug gage reference standards that bound the lower and upper values of the measurements. The diameter standards are verified, traceable to a NIST standard. The uncertainty of the azimuthal orientation is $< \pm 5.0^{\circ}$, and the uncertainty of the axial position is \pm 0.005 in. $(0.13 \mathrm{~mm})$.

As-built inspection of the fuel rodlets performed by a qualified inspector included diameter measurements at four axial locations and two rotations each. All diameter measurements confirmed that the rodlets were within specification of $0.230 \pm 0.001$ in., as shown in Table 7 .

Table 7. As-built Rodlet Diameter Measurements

\begin{tabular}{|l|c|c|c|c|c|c|}
\hline & \multicolumn{7}{|c|}{ Rodlet Outer Diameter (in.) } \\
\hline Rodlet & 2CR1 & 2CR2 & 2CR3 & 2CR4 & 2CR5 & 2CR6 \\
\hline Minimum & 0.2293 & 0.2293 & 0.2293 & 0.2293 & 0.2292 & 0.2293 \\
\hline Maximum & 0.2295 & 0.2294 & 0.2294 & 0.2294 & 0.2294 & 0.2294 \\
\hline Average* & 0.2294 & 0.2293 & 0.2294 & 0.2294 & 0.2293 & 0.2293 \\
\hline
\end{tabular}

* average of all 8 diameter measurements (rounded to $0.0001 \mathrm{in.)}$

Table 8. Rodlet Diameter Measurement Test Parameters

\begin{tabular}{|c|c|c|c|}
\hline Specimen & Z-Range (wrt bottom) & Azimuthal Orientation & Z-step Interval \\
\hline \multirow{2}{*}{ AFC-2C $(6$ rodlets $)$} & $0.4-5.5 \mathrm{in}$. & Five Scans: & $0.10 \mathrm{in}$. \\
& $(1.0-14 \mathrm{~cm})$ & $0^{\circ}, 45^{\circ}, 90^{\circ}, 135^{\circ}, 180^{\circ}$ & $(0.25 \mathrm{~cm})$ \\
\hline
\end{tabular}

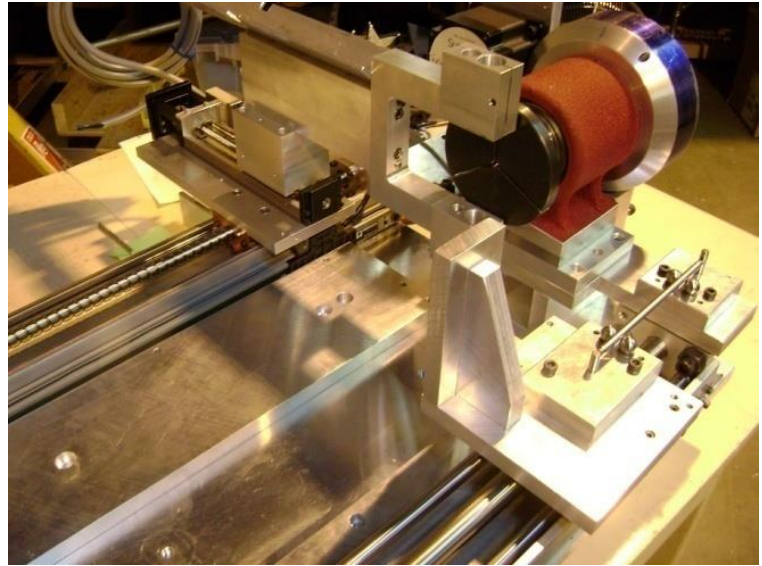

a) length measurement setup

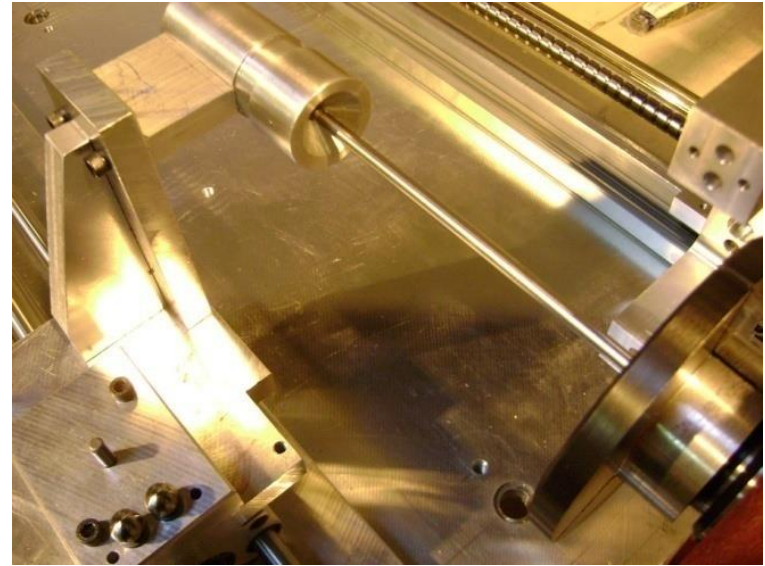

b) diameter measurement setup

Figure 10. Remote Fuel Metrology Unit 
Figure 11 through Figure 16 show the diameter profilometry for the AFC-2C rodlets $(0$ in. is at the bottom or fuel region of the rodlet). The data show apparent swelling in the fuel region of rodlets $2 \mathrm{CR} 3$ and 2CR4. Rodlets 2CR1 and especially 2CR4 show some ovality, indicated by expanded and reduced diameters at the same axial location and approximately $90^{\circ}$ apart. Spikes of $0.001-0.005$ in. are observed for all rodlets, but are not consistent with rodlet rotation and are likely surface matter adhereing to the rodlets.

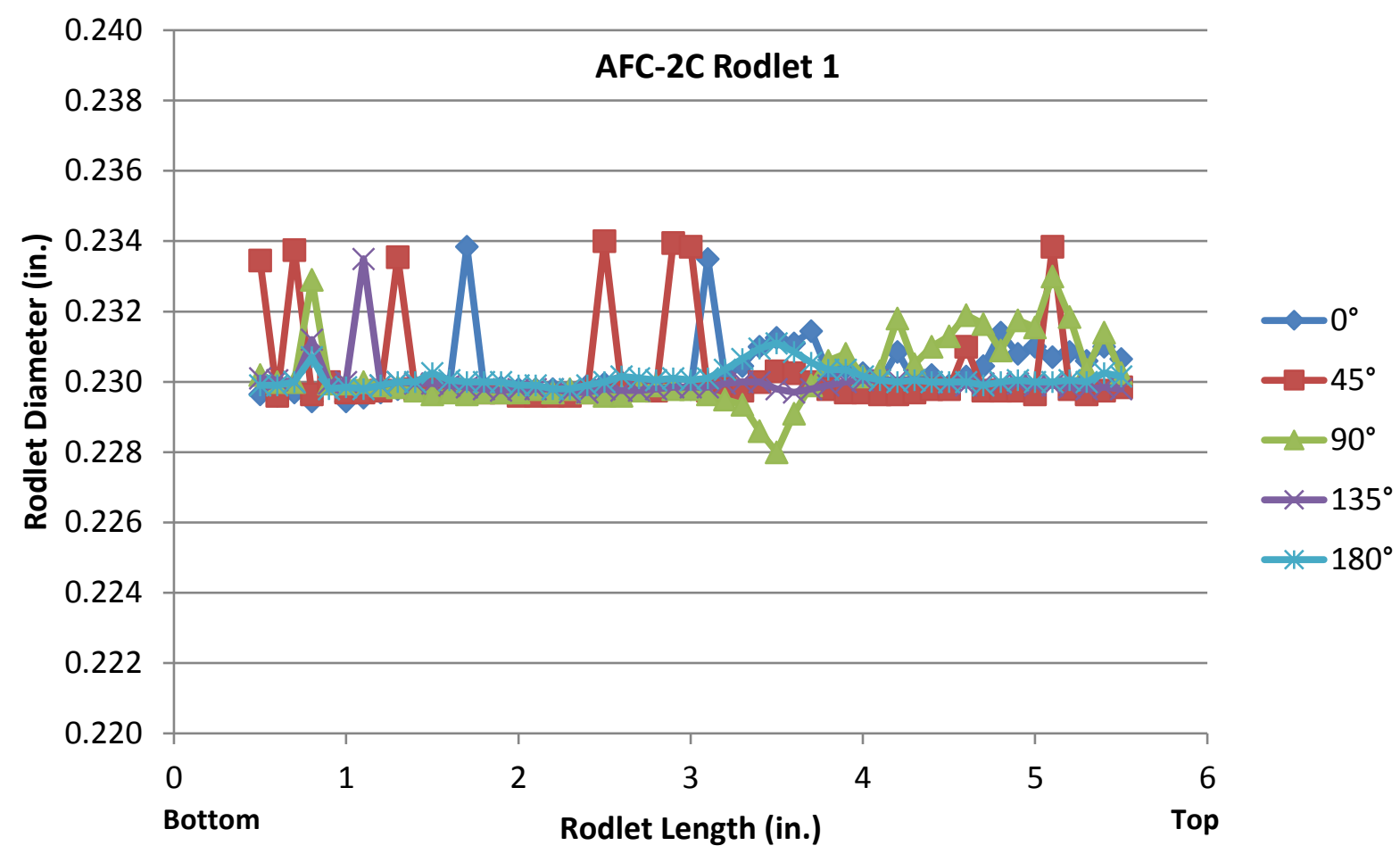

Figure 11. Diameter Profilometry of 2CR1 


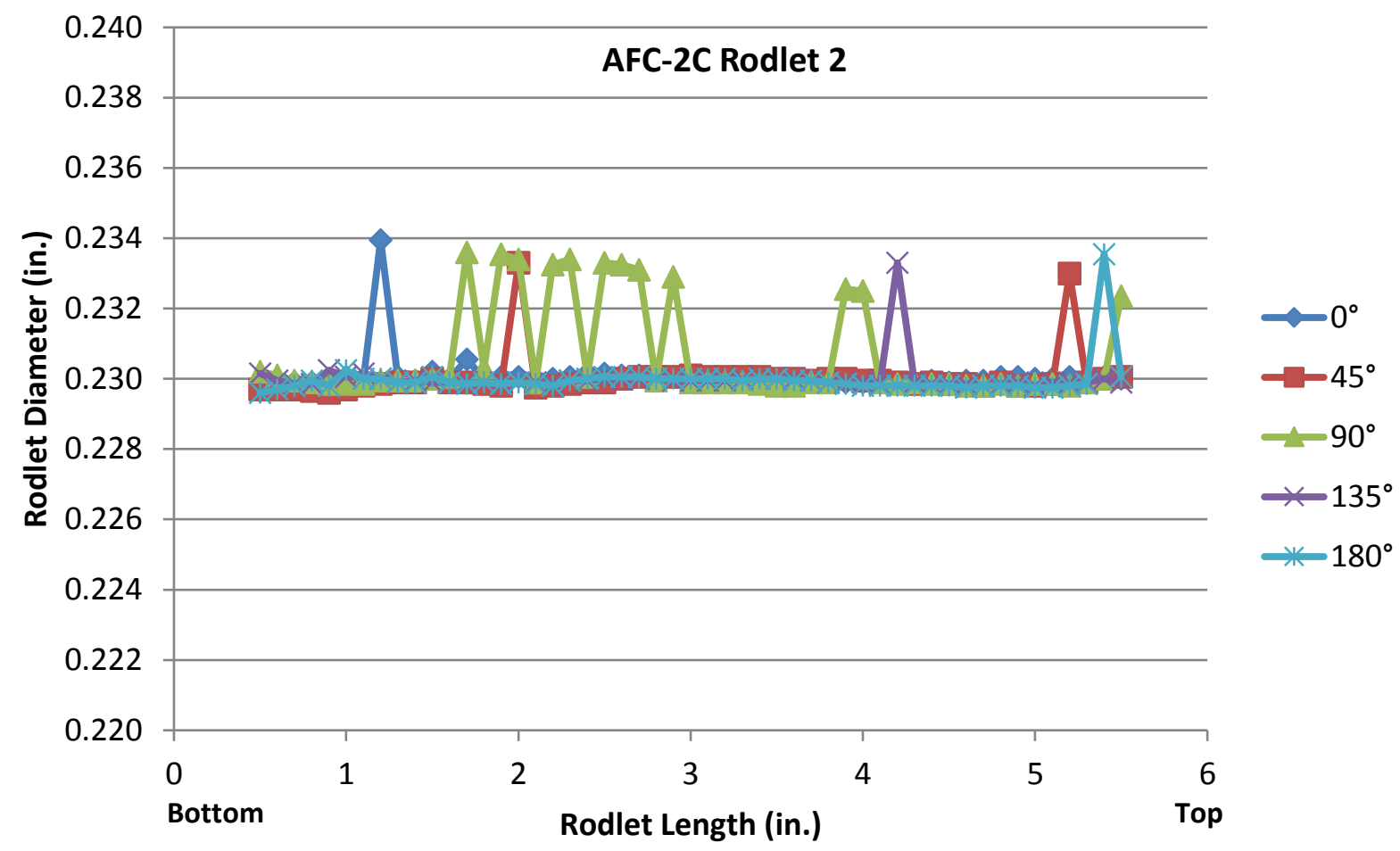

Figure 12. Diameter Profilometry of 2CR2

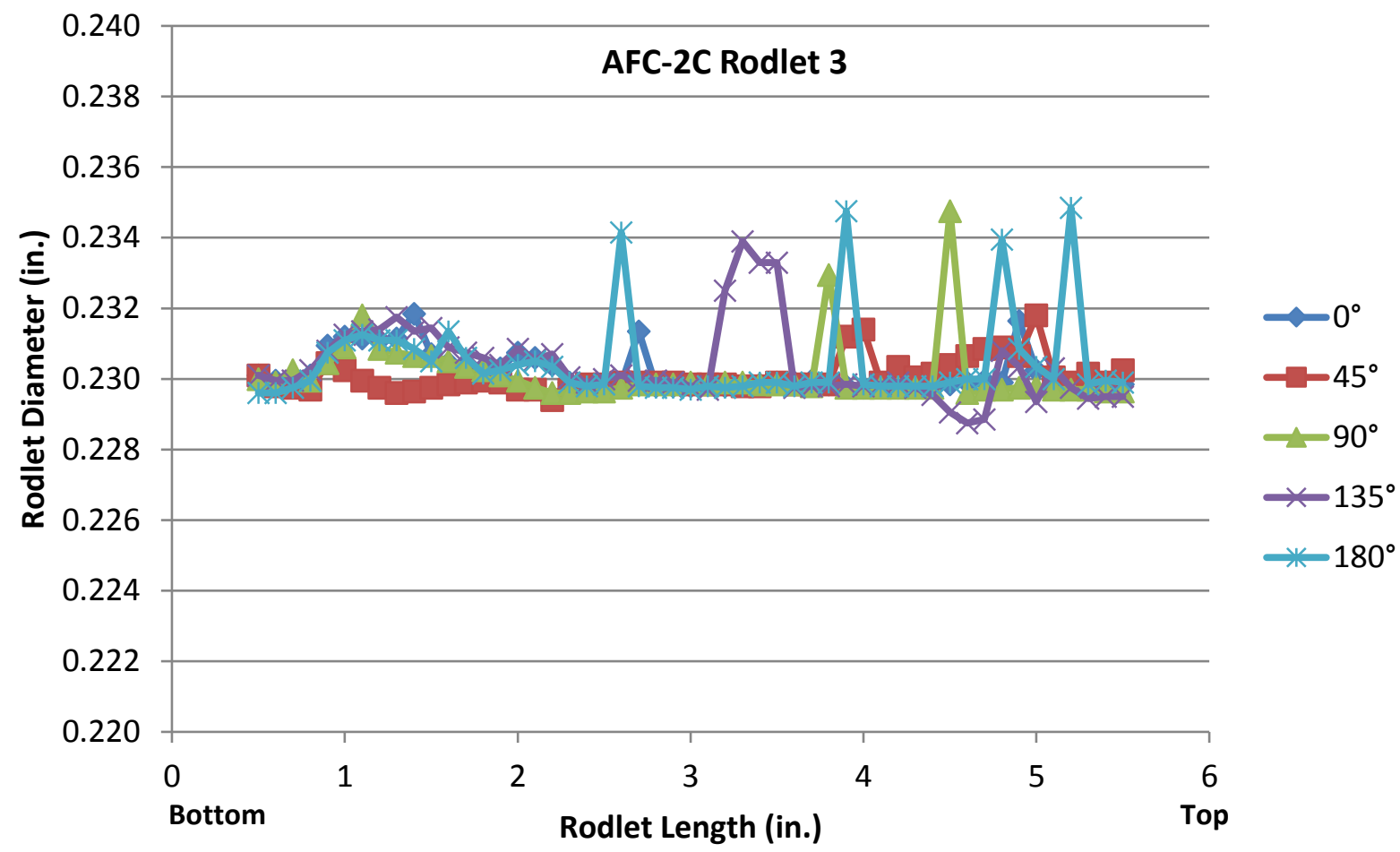

Figure 13. Diameter Profilometry of 2CR3 


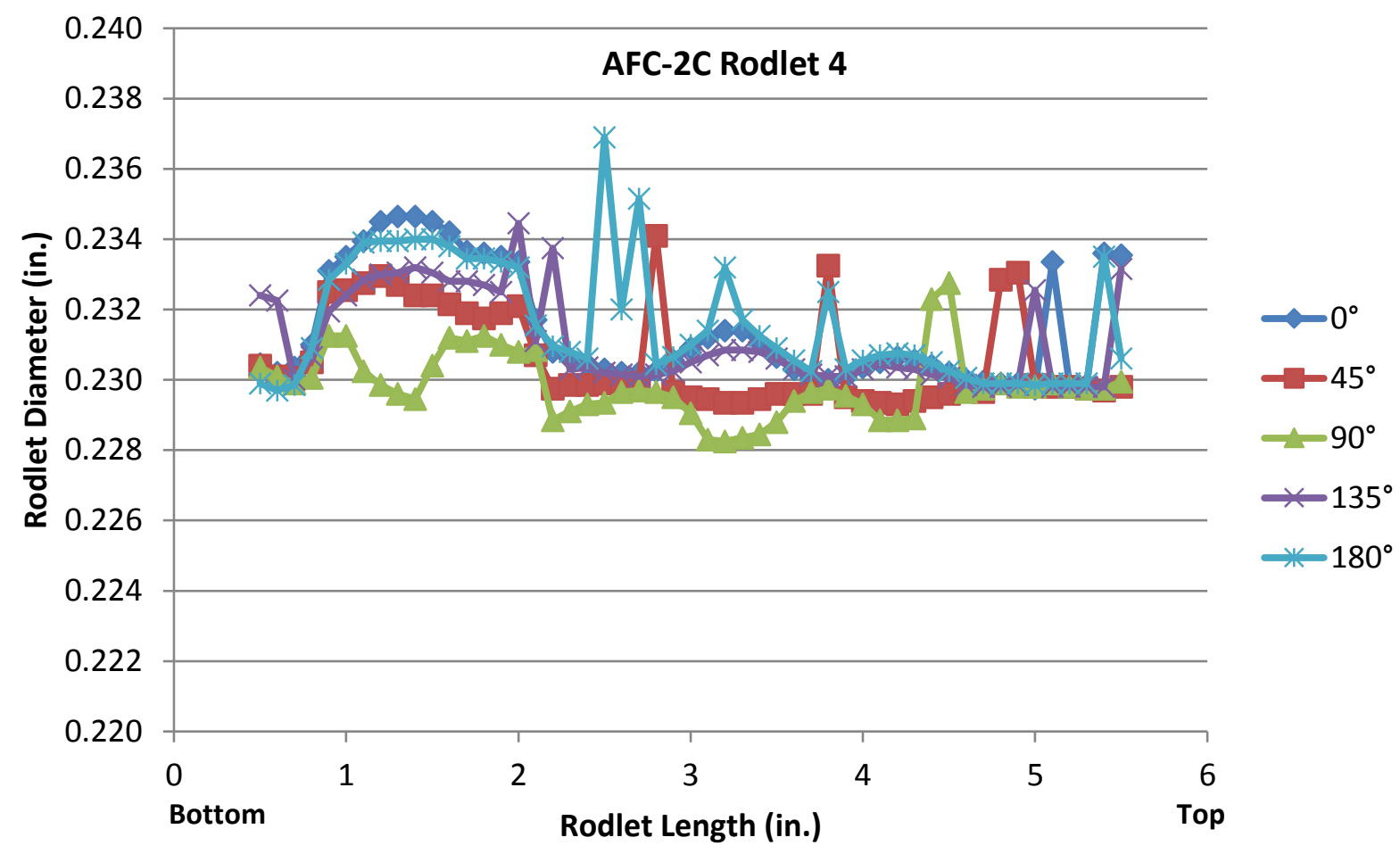

Figure 14. Diameter Profilometry of 2CR4

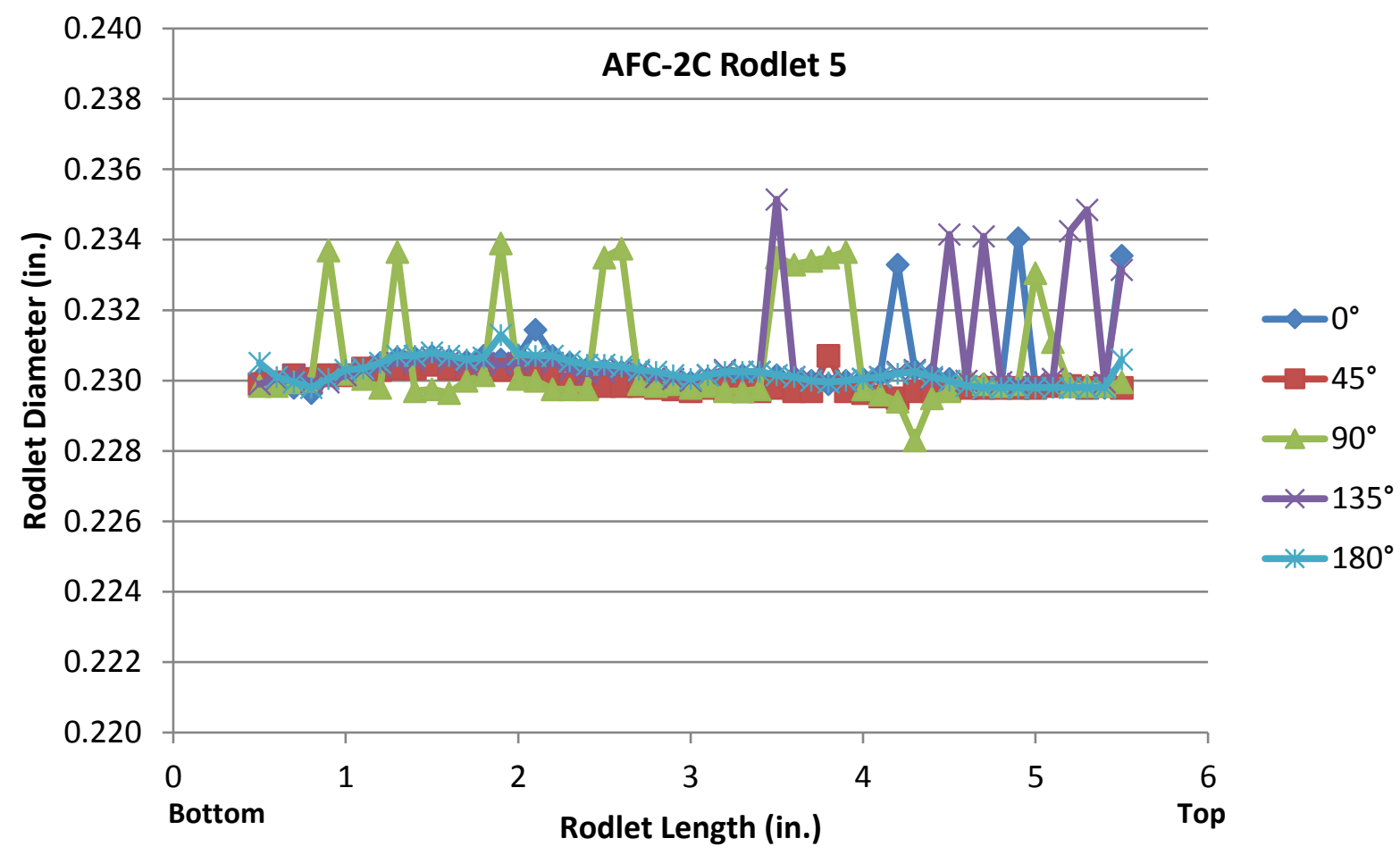

Figure 15. Diameter Profilometry of 2CR5 


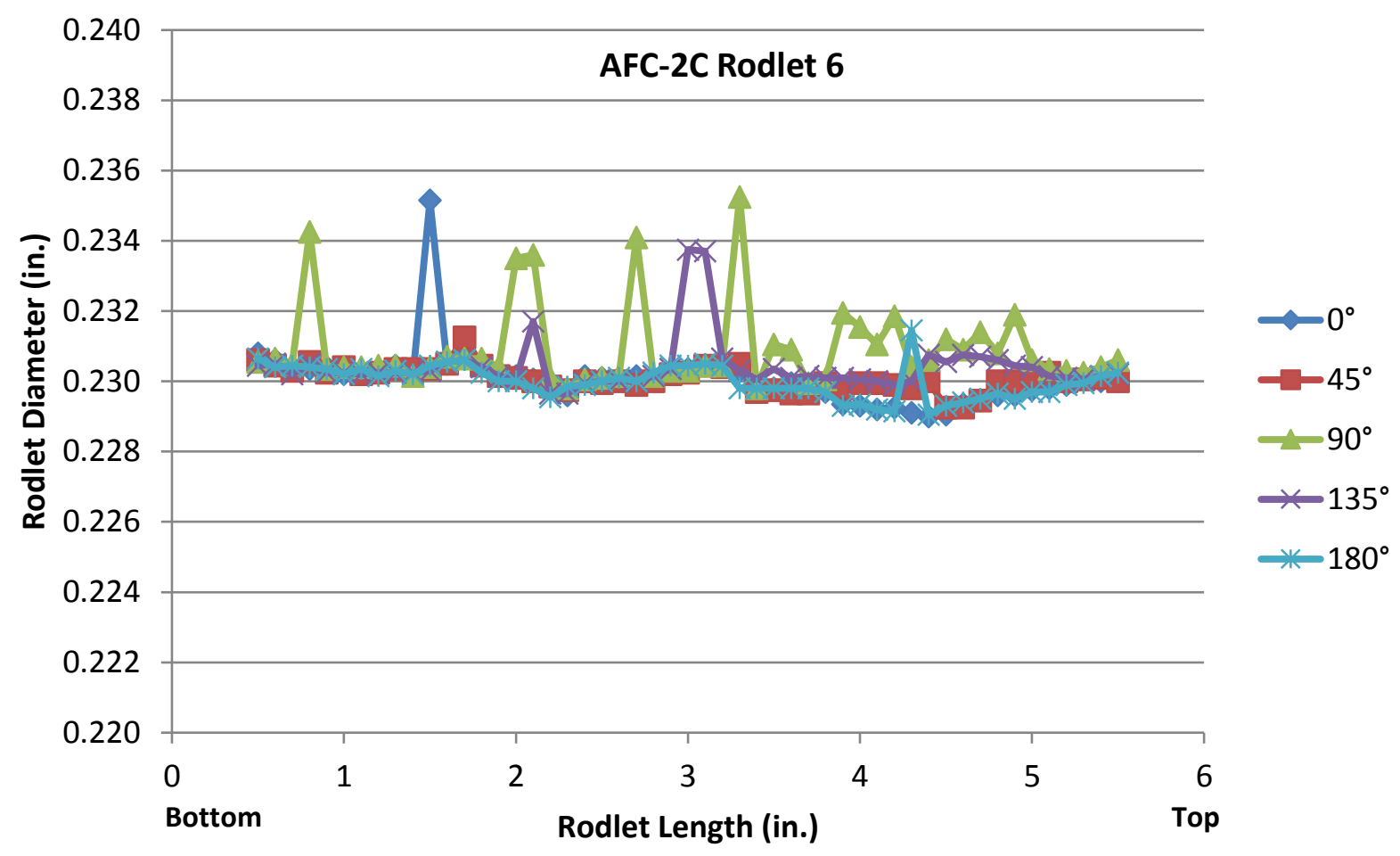

Figure 16. Diameter Profilometry of 2CR6

\subsection{Gamma Scan}

Gamma scans were performed with the PGS-III at HFEF Window 7M. The test parameters are detailed in Table 9. Gamma scans were collected on all rodlets from AFC-2C. The six rodlets were placed in an aluminum tube for ease of handling with a stainless steel ball between each rodlet to indicate the interfaces between rodlets. The gamma scans recorded gross (total) and isotopic data the full length of the fuel rod at 0.10 in. $(0.25 \mathrm{~cm})$ intervals. The scan time at each axial position was $120 \mathrm{sec}$ with a collimator width of 0.10 in. $(0.25 \mathrm{~cm})$. The PGS-III primary gamma-spectra detector and measurement uncertainty are described in Section 3.3.

Figure 17 through Figure 22 show the axial gamma scans for each rodlet (note that 0 in. is near the top of each rodlet with the fuel region at approximately 4-6 in.). Recall that ${ }^{134} \mathrm{Cs}$ and ${ }^{137} \mathrm{Cs}$ reflect very mobile fission products, transported by gaseous and liquid phase transport, ${ }^{144} \mathrm{Ce}$ and ${ }^{144} \mathrm{Pr}$ represents lanthanide fission products which are moderately mobile and tend to migrate down temperature gradients within the fuel, and ${ }^{95} \mathrm{Nb},{ }^{95} \mathrm{Zr}$, and ${ }^{106} \mathrm{Ru}$ represent non-mobile fission products. ${ }^{54} \mathrm{Mn}$ and ${ }^{60} \mathrm{Co}$ are activation products within the rodlet cladding and endplugs.

Gamma scans of the AFC-2C rodlets show no unusual behavior. The ${ }^{95} \mathrm{Nb},{ }^{106} \mathrm{Rh}$ and ${ }^{144} \mathrm{Pr}$ signals are consistent with the original stack of MOX fuel pellets. The ${ }^{137} \mathrm{Cs}$ signal extends above and below the fuel stack, into the depleted $\mathrm{UO}_{2}$ insulator pellets, suggesting that mobile fission products have migrated from the active fuel stack into the insulator pellets. 
Table 9. Rodlet Gamma Scan Test Parameters

\begin{tabular}{|c|c|c|c|c|}
\hline Specimen & Z-Range & $\begin{array}{c}\text { Scan } \\
\text { Time }\end{array}$ & \multicolumn{1}{|c|}{ Spectra Analysis } & $\begin{array}{c}\text { Z-step Interval } \\
\text { Collimator Width }\end{array}$ \\
\hline AFC-2C & Full length & $120 \mathrm{~s}$ & $\begin{array}{l}\text { Gross } \begin{array}{l}(\text { total }) \\
\text { Isotopics }\left({ }^{54} \mathrm{Mn},{ }^{60} \mathrm{Co},{ }^{95} \mathrm{Zr},{ }^{95} \mathrm{Nb},{ }^{103} \mathrm{Ru},\right.\end{array} \\
\left.{ }^{134} \mathrm{Cs},{ }^{137} \mathrm{Cs},{ }^{144} \mathrm{Ce},{ }^{14} \mathrm{Pr}\right)\end{array}$ & 0.10 in. $(0.25 \mathrm{~cm})$ \\
\hline
\end{tabular}

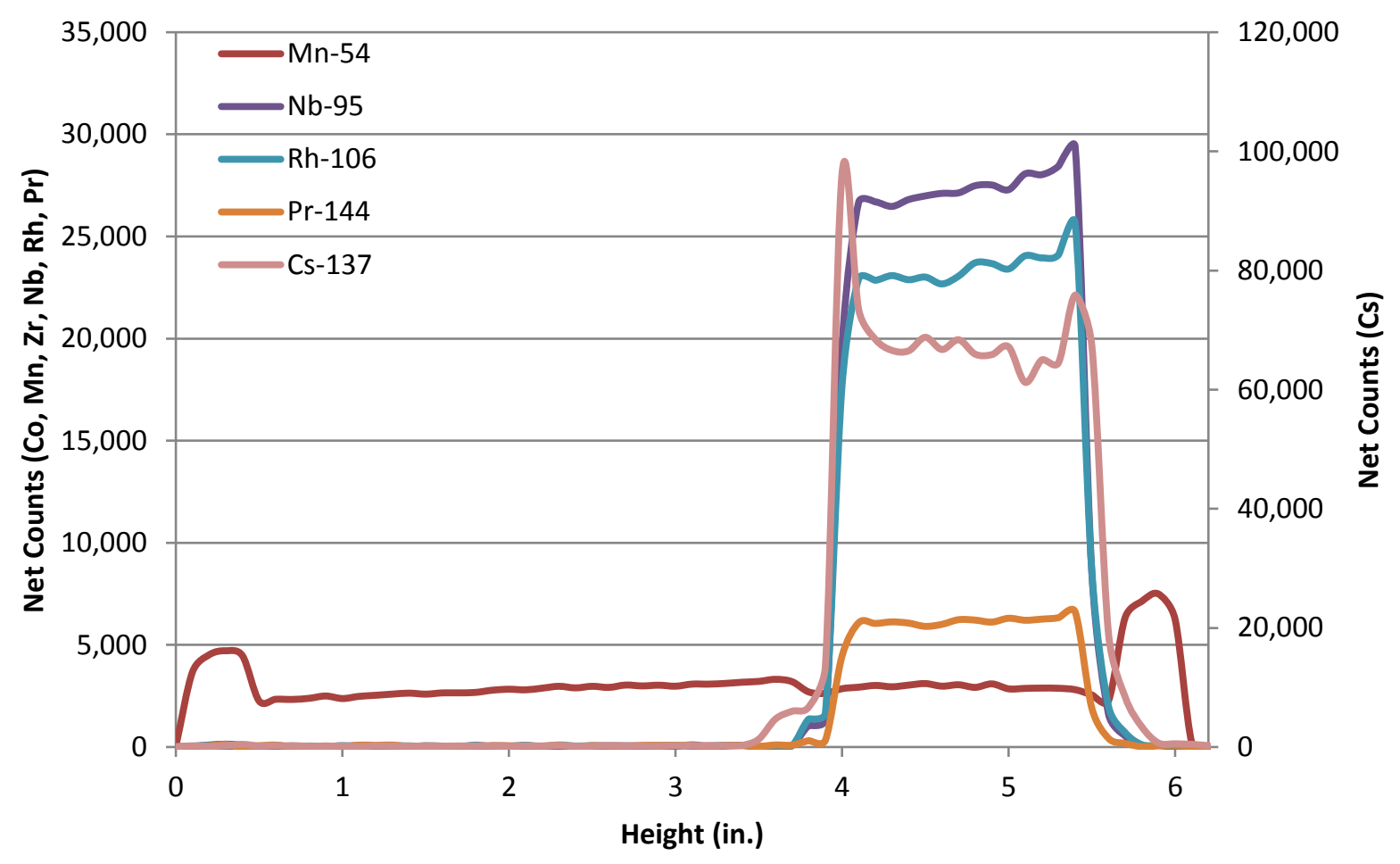

Figure 17. Gamma Scan of 2CR1 


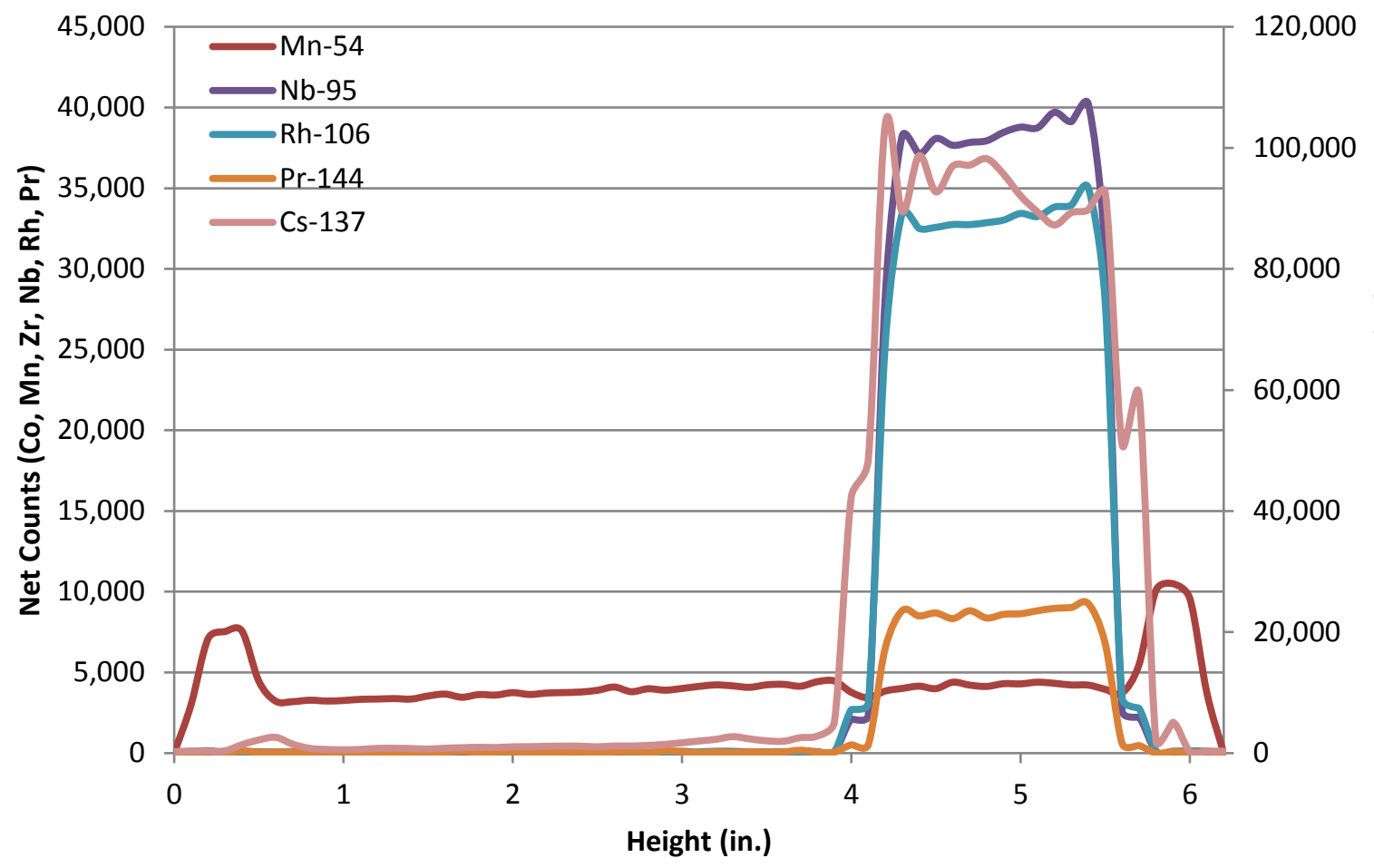

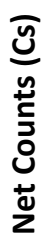

Figure 18. Gamma Scan of 2CR2

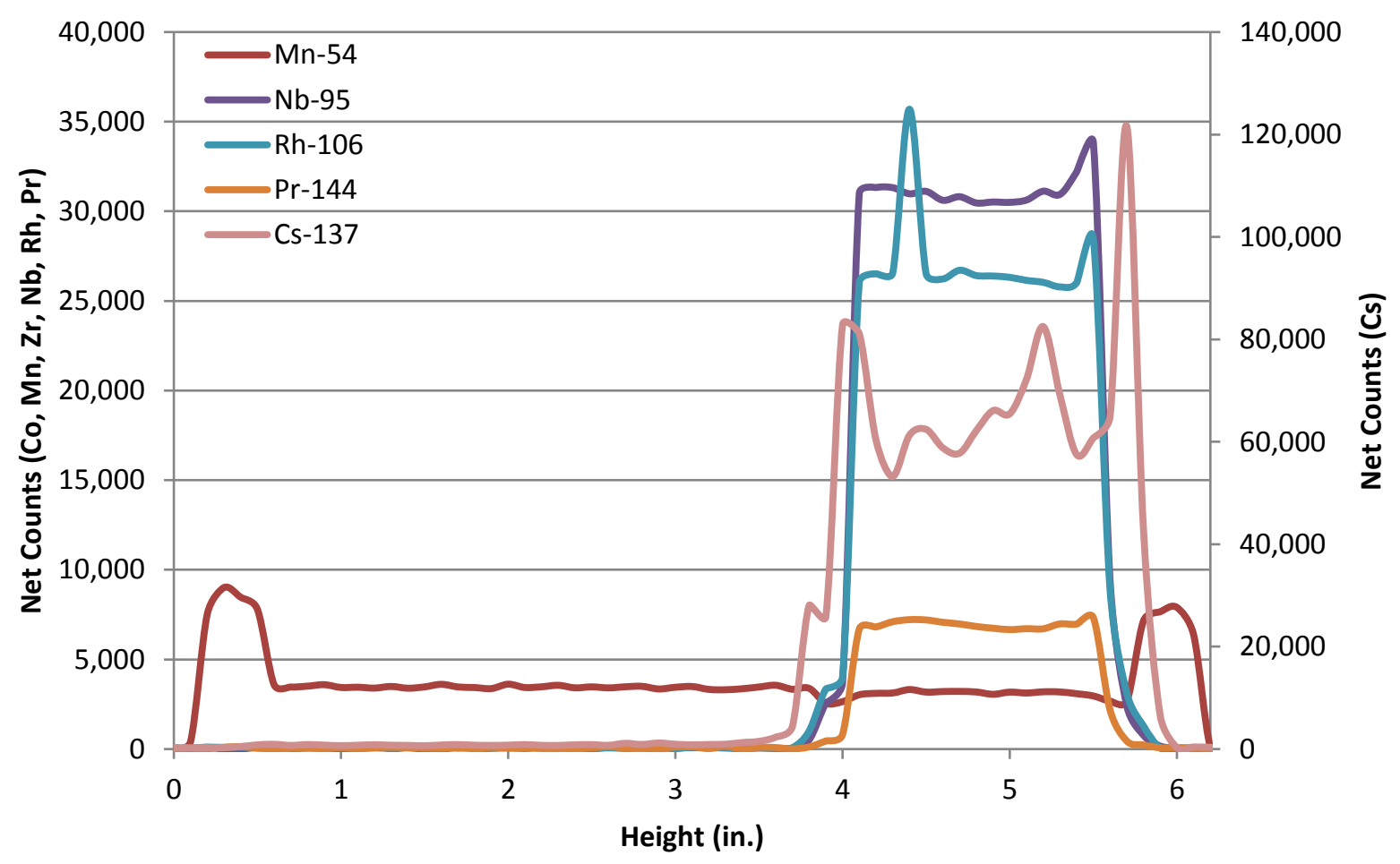

Figure 19. Gamma Scan of 2CR3 


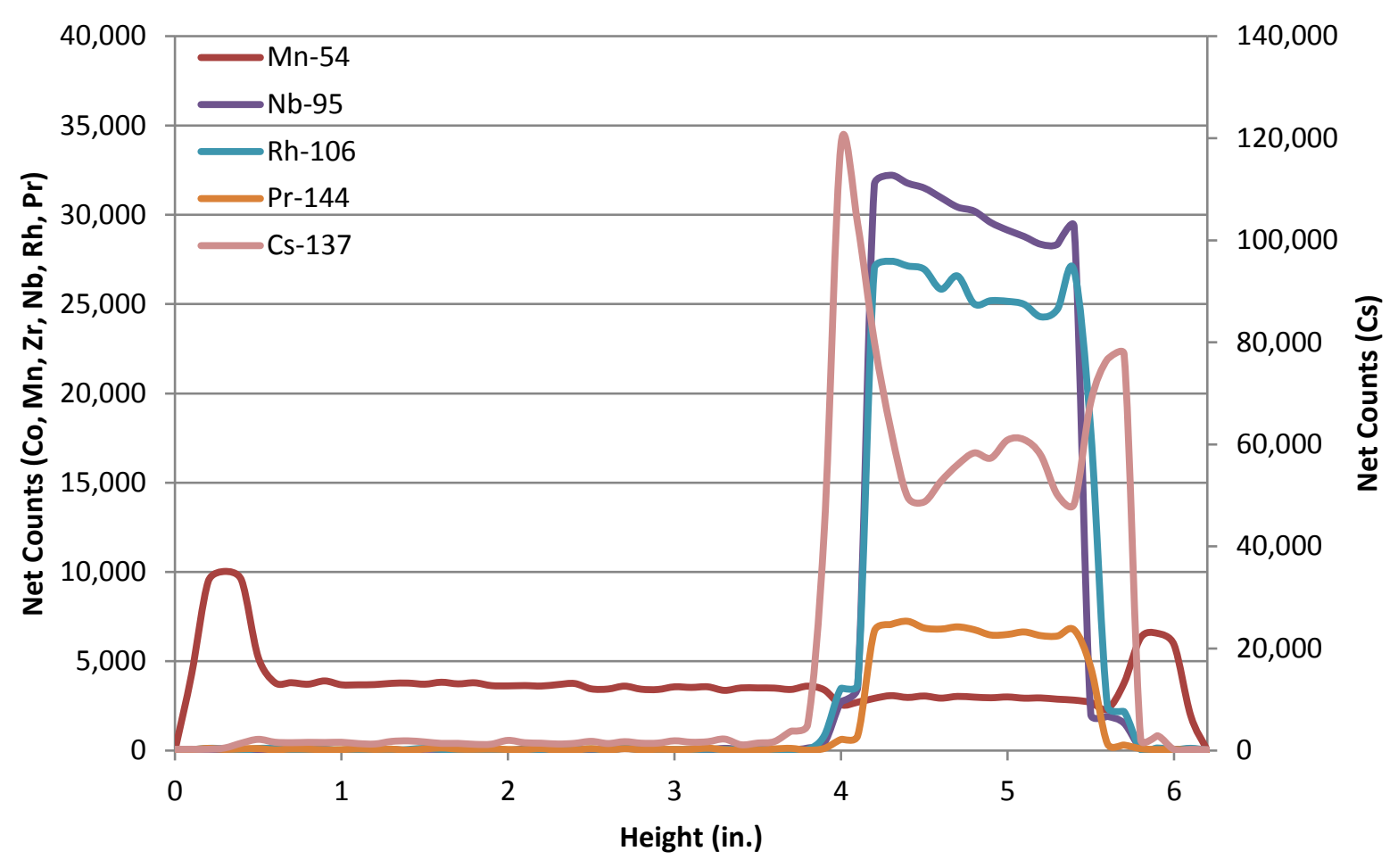

Figure 20. Gamma Scan of 2CR4

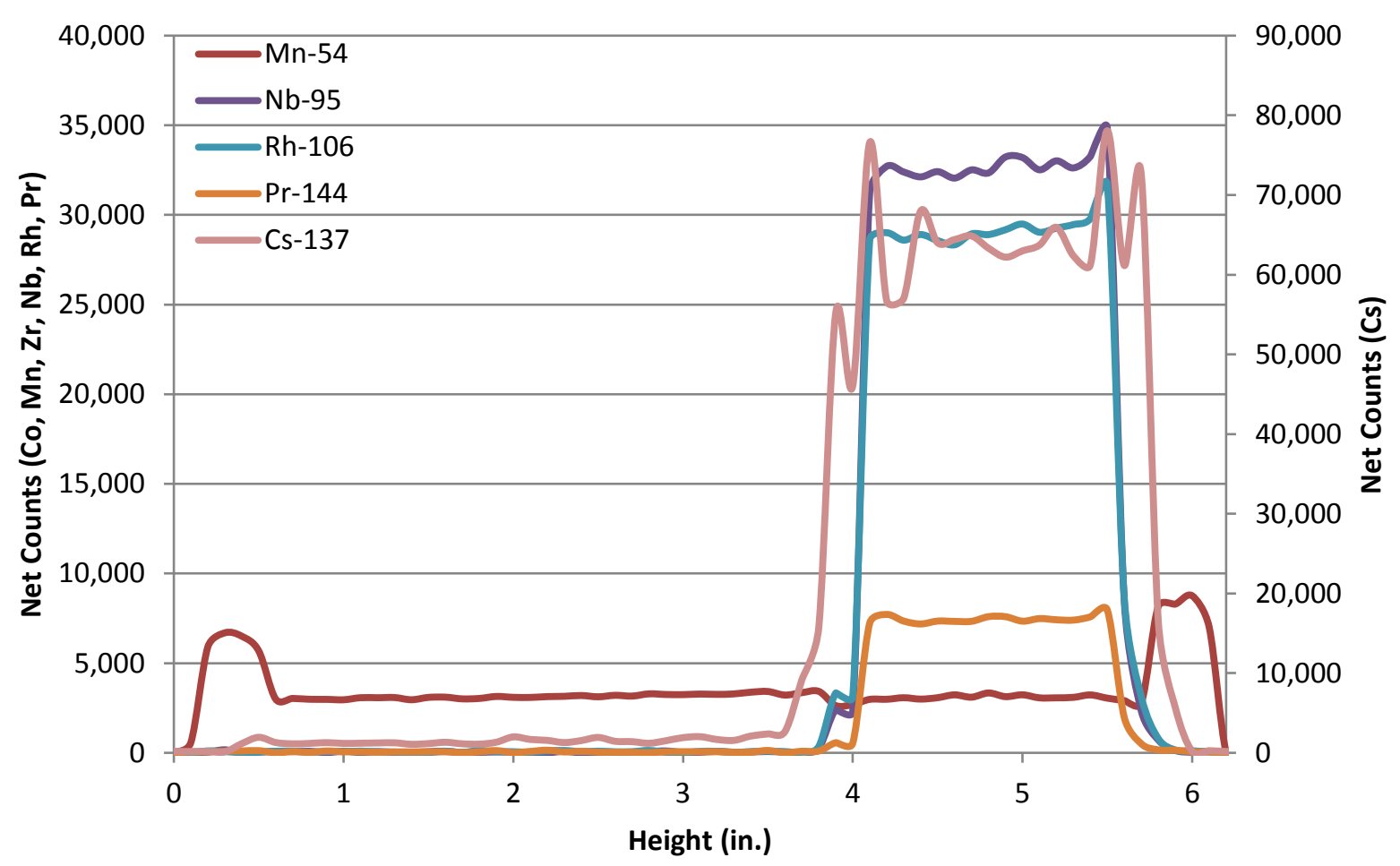

Figure 21. Gamma Scan of 2CR5 


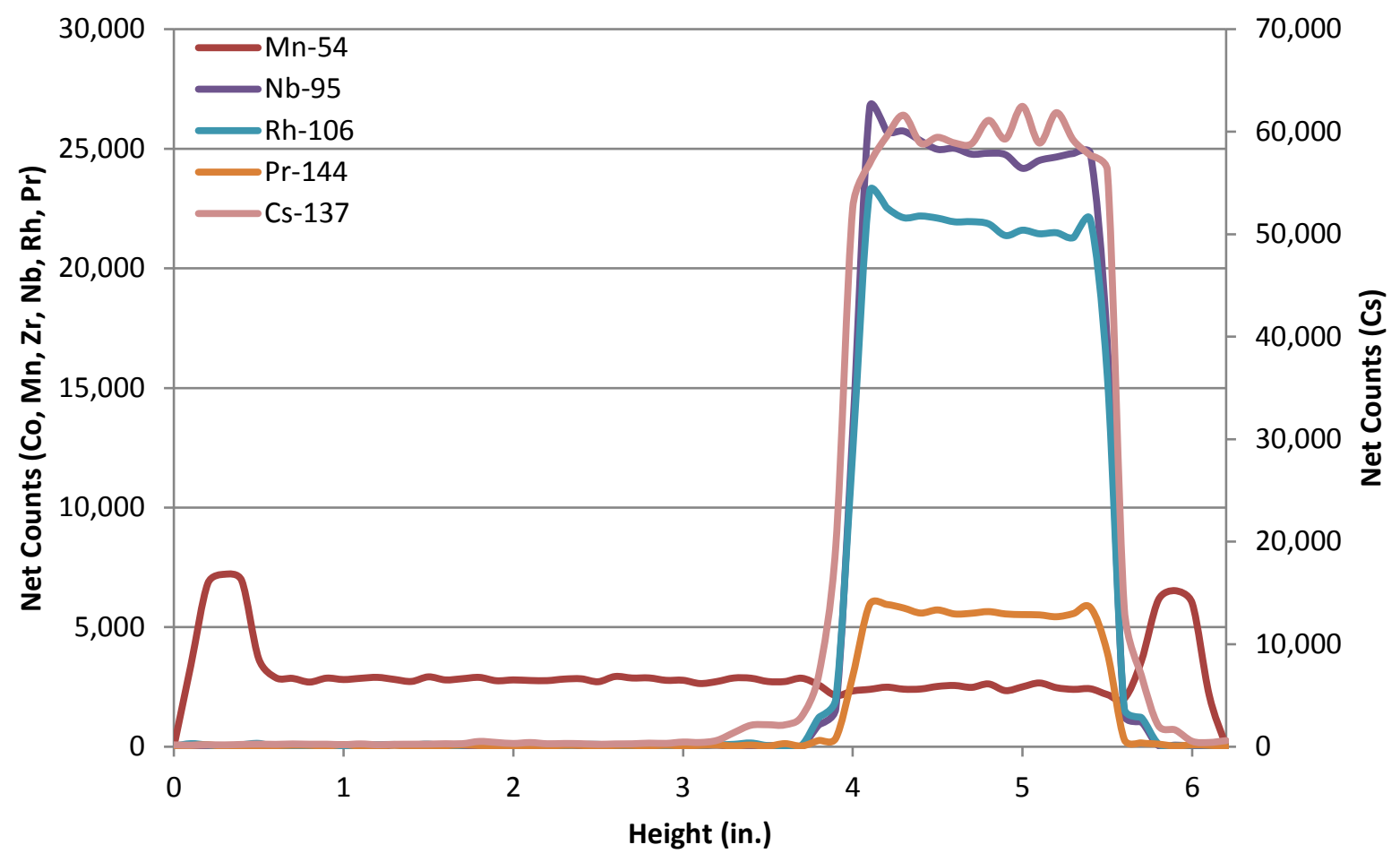

Figure 22. Gamma Scan of 2CR6

\section{RODLET DESTRUCTIVE EXAMINATIONS}

Only four of the six AFC-2C rodlets went through destructive examinations; two rodlets (2CR1 and 2CR4) were saved for possible future advanced non-destructive PIE techniques.

\subsection{Fission Gas Analysis}

Fission gases were collected from the rodlets using the HFEF Gas Assay, Sample, and Recharge (GASR) system. Rodlets were punctured using a $150 \mathrm{~W}$ Nd-YAG laser system and a gas sample is collected in a stainless steel bottle external to the hot cell. Void volume in the rodlet was then determined by a series of backfills into the punctured rodlet and expansions into the GASR system. The fuel rodlet internal gas pressure was derived from the void volume measurement and the initial gas pressure measurement upon puncture. Results of fission gas analysis provided total elemental composition and krypton and xenon isotopic composition. A summary of results is shown in Table 10.

The four AFC-2C rodlets subjected to puncture and gas analysis were intact and contained fission gases. Comparison of these results to other fast reactor MOX fuels will be performed as future work. 
Table 10. Fission Gas Release Summary

\begin{tabular}{|c|c|c|c|c|c|c|c|c|c|c|}
\hline \multirow{2}{*}{ Rodlet } & \multirow{2}{*}{$\begin{array}{l}\text { Plenum } \\
\text { Pressure } \\
\quad(\mathrm{psi})\end{array}$} & \multirow{2}{*}{$\begin{array}{c}\text { Plenum } \\
\text { Volume } \\
\left(\mathrm{cm}^{3}\right)\end{array}$} & \multicolumn{6}{|c|}{ Gas Composition - Major Components (\%) } & \multirow{2}{*}{$\begin{array}{c}\mathrm{Kr}+\mathrm{Xe} \\
\text { Gas } \\
\text { Release } \\
(\%)\end{array}$} & \multirow{2}{*}{$\begin{array}{c}\text { He } \\
\text { Gas } \\
\text { Release } \\
(\%)\end{array}$} \\
\hline & & & He & $\mathbf{N}$ & O & Ar & $\mathbf{K r}$ & $\mathbf{X e}$ & & \\
\hline \multicolumn{11}{|l|}{ 2CR1 } \\
\hline 2CR2 & 57.4 & 1.4683 & 26.9 & 0.05 & 0.001 & 0.595 & 8.19 & 64.0 & 50.9 & 48.3 \\
\hline 2CR3 & 145.5 & 1.3397 & 32.9 & 0.011 & $<0.001$ & 0.291 & 7.3 & 59.4 & 100 & $>100$ \\
\hline \multicolumn{11}{|l|}{ 2CR4 } \\
\hline 2CR5 & 112.1 & 1.3305 & 40.7 & 0.035 & $<0.001$ & 0.341 & 6.56 & 52.3 & 64.5 & 96.4 \\
\hline 2CR6 & 60.0 & 1.3248 & 59.7 & 0.066 & $<0.001$ & 0.576 & 4.55 & 34.9 & 28.5 & 78.1 \\
\hline
\end{tabular}

\subsection{Metallography}

Fuel microstructure was investigated using optical microscopy, also referred to as metallography. Rodlets were sectioned through the fuel zone in order to create samples for optical microscopy. Cross-sections about $2 \mathrm{~mm}(0.35 \mathrm{in}$.) in length were cut, mounted in epoxy, and polished to a $0.25 \mu \mathrm{m}$ finish at HFEF Window 2M (Containment Box). Optical microscopy was performed on a Leitz MM5RT metallograph installed in a shielded inert atmosphere (nitrogen) alpha containment hot cell. Images were recorded using an integrated digital camera with 2-6 megapixel resolution in black and white 8-bit grayscale format. Full cross-section montages were compiled from individual 50X images. Higher magnification images also were recorded of features of interest.

Radial cross-sections were taken from the midplane or slightly below midplane of the fuel column; samples were not taken near the ends in order to avoid possible peaking or end effects. Cross-sections were cut using a slow speed saw.

Figure 23 shows AFC-2C metallography. Characteristic central void formation and fuel restructuring is seen in 2CR2, 2CR3 and 2CR5. Fast reactor oxide fuels typically operate with fuel centerline temperatures greater than $1700^{\circ} \mathrm{C}$, leading to fuel restructuring with a central void and radial zone formation. That these features are seen in the AFC-2C experiment indicates that the experiments are achieving prototypic power and temperature profiles in the ATR experiment assembly utilizing a cadmium filter. The central void in 2CR3 (Figure 23b) is slightly offset from the center. This is likely due to the rodlet not being exactly centered in the capsule; however the fuel still reaches prototypic temperatures necessary to achieve restructuring. 


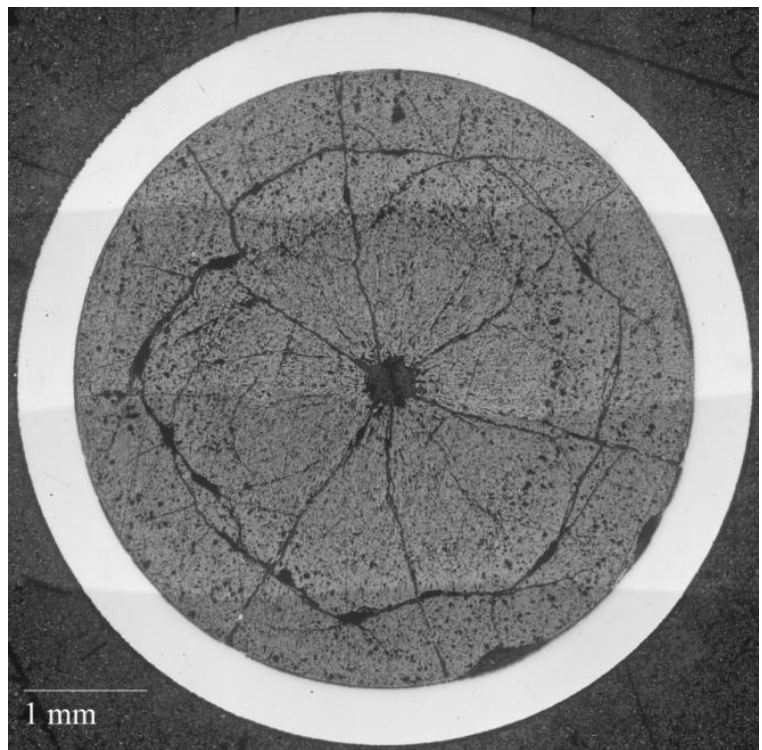

a) 2CR2 (MNT 118T)

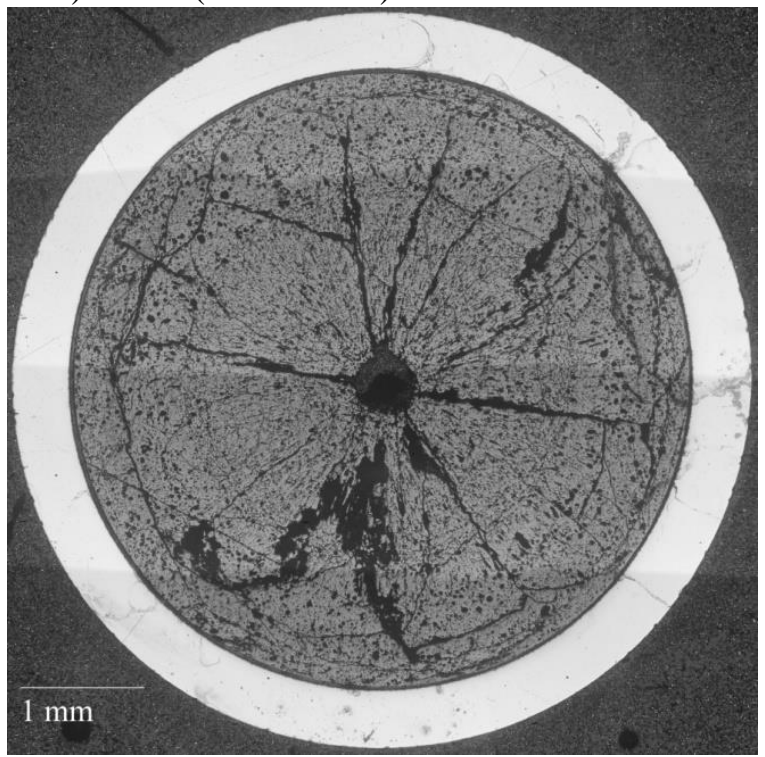

c) 2CR5 (MNT 105T)

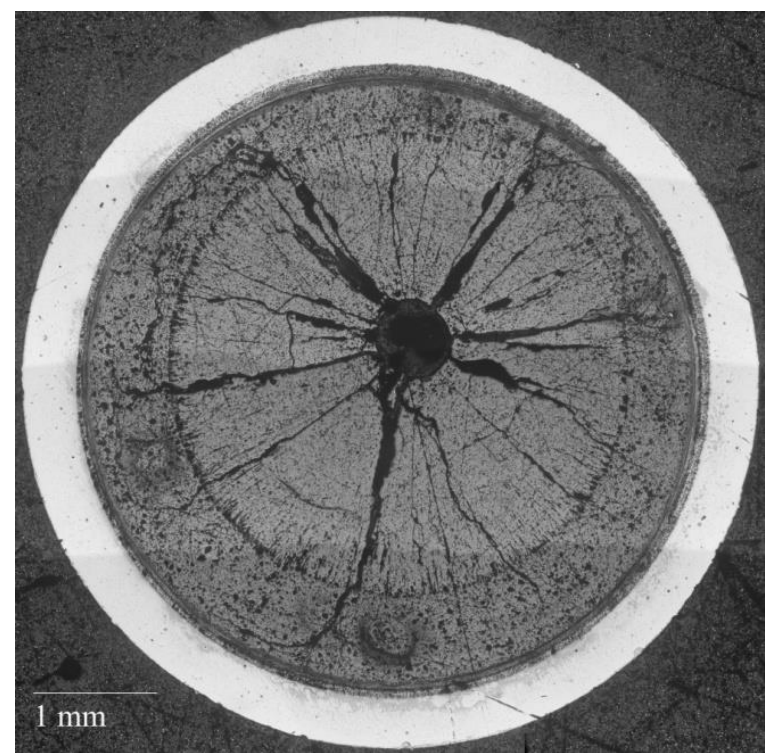

b) 2CR3 (MNT 104T)

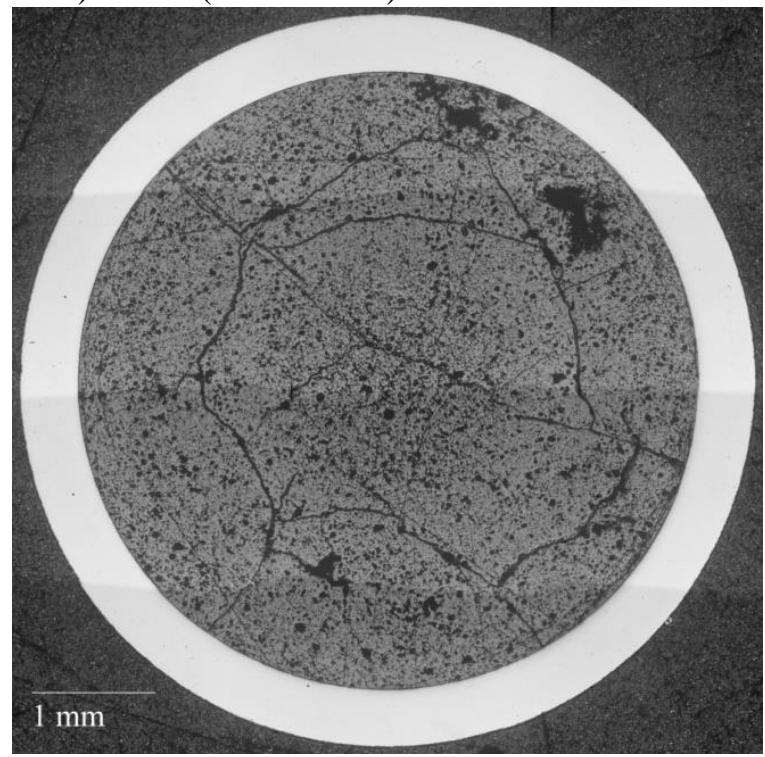

d) 2CR6 (MNT 106T)

Figure 23. AFC-2C Optical Microscopy (images recorded at 50X magnification)

\subsection{Microhardness}

Microhardness testing was performed on the fuel met mounts using a LECO AMH43 microindentation hardness testing system installed in a shielded inert atmosphere alpha containment hot cell. Room temperature microhardness tests using a Vickers diamond pyramid were performed with a nominal load of $100 \mathrm{~g}$. Microhardness tests were performed at four or more azimuthal orientations around the sample cross-section with five locations across the cladding wall and five locations into the fuel.

The primary intent of microhardness testing is to identify changes in cladding mechanical properties that may be due to interaction between fuel and cladding. Decreases in cladding hardness (softening) indicate cladding decarburization. Increases in cladding hardness (hardening) indicate FCCI between rare earth elements and the cladding. 
Microhardness measurements vary between rodlets and within measurement paths, as shown in Table 11 with accompanying metallography indicating select measurement locations shown in Figure 24. Neither the microhardness data nor optical microscopy show indications of FCCI in the AFC-2C rodlets. Additional PIE (beyond baseline) is required to look for other signs of FCCI.

Table 11. AFC-2C Microhardness Values

\begin{tabular}{|c|c|c|c|c|c|c|c|c|c|}
\hline \multirow{2}{*}{ Rodlet } & \multirow{2}{*}{ Spot } & \multicolumn{4}{|c|}{ Cladding Hardness (HV) } & \multicolumn{4}{|c|}{ Fuel Hardness (HV) } \\
\hline & & North & East & South & West & North & East & South & West \\
\hline \multirow{5}{*}{ 2CR2 } & 1 & 300.2 & 279.5 & 310.6 & 296.1 & 321.2 & 312.7 & 942.5 & 185.2 \\
\hline & 2 & 315.2 & 298.1 & 320.3 & 316.5 & 475.5 & 75.3 & 491.9 & 205.4 \\
\hline & 3 & 311.4 & 310.5 & 316.0 & 302.1 & 536.8 & 687.2 & 782.6 & 660.4 \\
\hline & 4 & 302.2 & 307.6 & 315.0 & 306.9 & 517.0 & 939.1 & 593.5 & 450.2 \\
\hline & 5 & 394.6 & 286.5 & 320.0 & 301.8 & 541.6 & 466.1 & 773.8 & 319.8 \\
\hline \multirow{5}{*}{ 2CR3 } & 1 & 288.3 & 280.7 & 259.7 & 264.7 & 206.8 & 465.9 & 270.4 & 105.0 \\
\hline & 2 & 282.6 & 278.9 & 253.3 & 263.0 & 745.0 & 315.9 & 808.9 & 312.9 \\
\hline & 3 & 175.2 & 261.4 & 261.4 & 256.4 & 891.8 & 670.9 & 737.8 & 852.9 \\
\hline & 4 & 275.2 & 245.5 & 242.5 & 256.4 & 979.4 & 1039.0 & 778.1 & 333.3 \\
\hline & 5 & 259.7 & 225.6 & 222.9 & 150.3 & 921.9 & 862.1 & & 994.3 \\
\hline \multirow{5}{*}{$2 \mathrm{CR} 5$} & 1 & 267.1 & 271.7 & 258.3 & 276.3 & 296.4 & 341.4 & 808.9 & 129.9 \\
\hline & 2 & 268.6 & 282.3 & 274.8 & 274.8 & 429.4 & 227.1 & 903.7 & 151.1 \\
\hline & 3 & 271.7 & 253.7 & 277.9 & 262.6 & 885.3 & 932.5 & 599.3 & 676.2 \\
\hline & 4 & 258.3 & 255.4 & 258.3 & 259.7 & 850.1 & 858.7 & 825.0 & 307.2 \\
\hline & 5 & 238.1 & 247.2 & 279.5 & 236.8 & 465.2 & 801.0 & 465.2 & 932.5 \\
\hline \multirow{5}{*}{ 2CR6 } & 1 & 324.1 & 296.1 & 296.1 & 302.2 & 633.8 & 388.4 & 778.1 & 538.1 \\
\hline & 2 & 306.4 & 317.3 & 317.3 & 308.6 & 491.9 & 778.1 & 815.3 & 721.5 \\
\hline & 3 & 358.8 & 306.4 & 312.9 & 308.6 & 643.8 & 179.7 & 647.6 & 778.1 \\
\hline & 4 & 292.2 & 315.1 & 315.1 & 304.3 & 420.3 & 778.1 & 392.1 & 604.4 \\
\hline & 5 & 300.2 & 310.7 & 310.7 & 300.2 & 655.2 & 256.4 & & 616.9 \\
\hline
\end{tabular}

Spot $1 \rightarrow 5$ : outer $\rightarrow$ inner

Indent load $=100 \mathrm{~g}$

hardness value not measured 


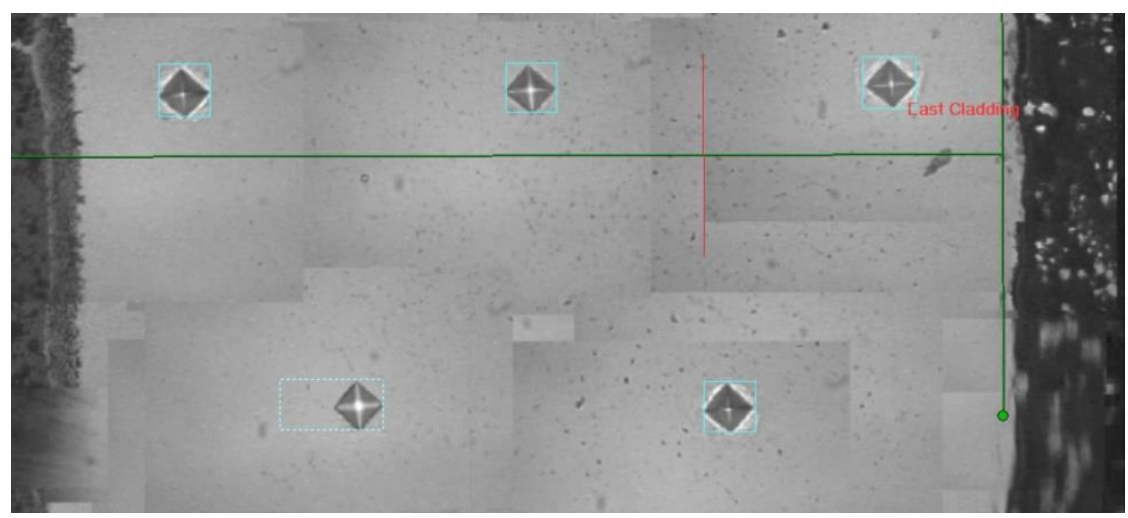

a) 2CR2 (MNT 118T) cladding east

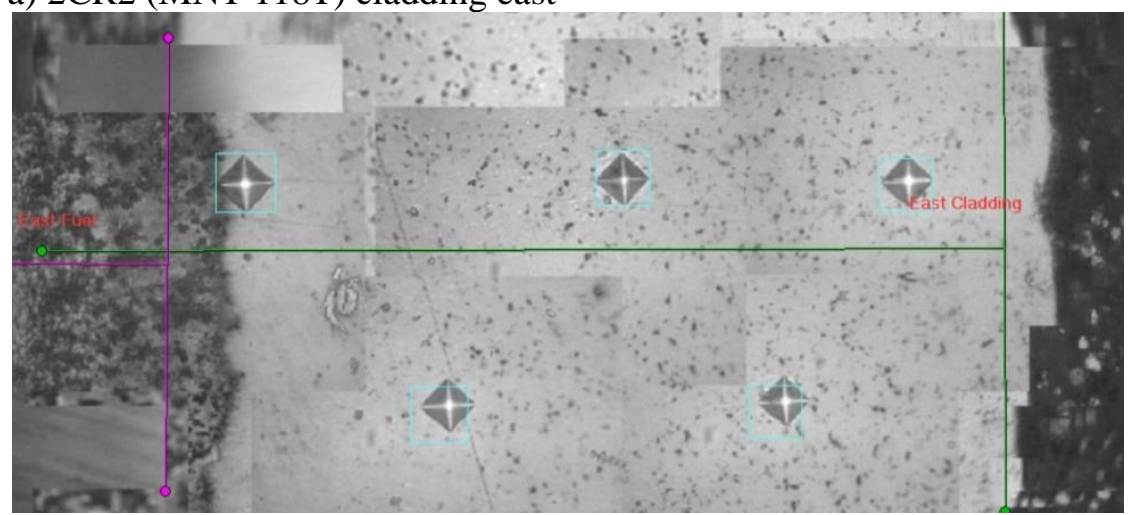

b) 2CR3 (MNT 104T) cladding east

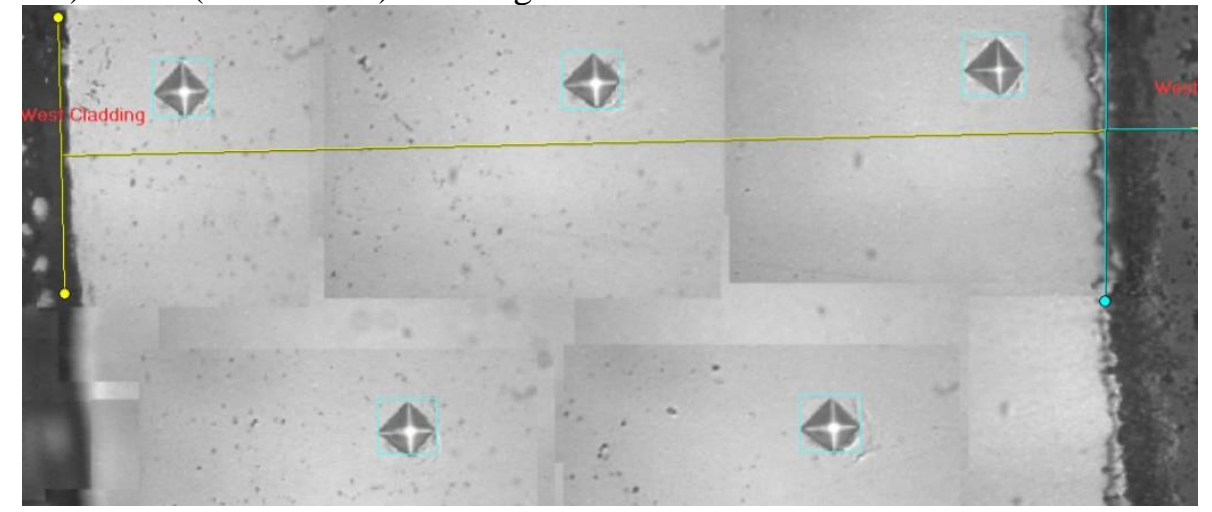

c) $2 \mathrm{CR} 5$ (MNT 105T) cladding west

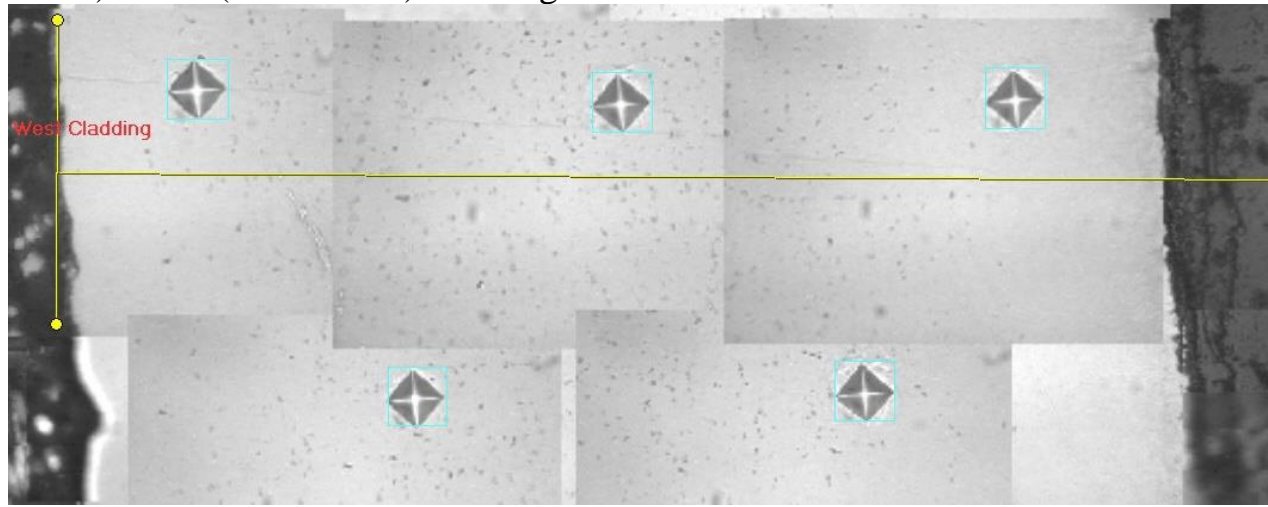

d) 2CR6 (MNT 106T) cladding west

Figure 24. AFC-2C Select Microhardness Testing Locations 


\subsection{Analytical Chemistry}

Samples were taken from each rodlet to measure base fuel component composition after irradiation, including $\mathrm{U}, \mathrm{Pu}, \mathrm{Am}, \mathrm{Np}, \mathrm{Cm}$, and $\mathrm{Zr}$, including the isotopic make-up of these base elements. In addition, an extensive chemical analysis for fission products was done. The goal was to determine heavy metal depletion, or fuel burnup, by noting the final heavy metal composition, or by comparing the expected accumulation of various fission products. Comparison of the measured compositions to code predictions will allow validation of code predictions for depletion, and will provide information about potential differences caused by the cadmium-filtered neutron spectrum in the AFC experiment assembly in ATR. To date, chemical analyses have been done but comparison to code predictions remains for future work scope.

Chemical analyses were done by dissolving cross-section (approximately $2 \mathrm{~mm}$ thick) from each rodlet including fuel, fission products, bond sodium and cladding. The fuel weight was gleaned from 1) subtracting the cladding weight determined by $\mathrm{Fe}$ and $\mathrm{Cr}$ content and bond sodium or 2) determined from the amount of $\mathrm{Zr}$ (after separating out the amount fission product $\mathrm{Zr}$ ). The former method was used to produce the composition data presented in this report. Inductively-coupled plasma mass spectrometry (ICP-MS) was used to measure the values shown in Table 15.

After irradiation $\sim 2 \mathrm{~mm}$ thick sections of fuel were cut and sent to the Analytical Laboratory hot cells for analysis. The fuel was dissolved for analysis, usually with the cladding unless it could be removed. ICPMS was used to measure the concentration of fuel (actinide) components, including a breakdown of the isotopic concentrations and fission products. Special separations were sometimes used to minimize the chance of interferences between isotopes of like atomic mass or they were reported as $144 \mathrm{~m} / \mathrm{Z}$, which could include several rare earth isotopes with atomic mass 144 .

Inductively-coupled plasma atomic emission spectrometry (ICP-AES) was used to determine the concentrations of cladding components ( $\mathrm{Fe}, \mathrm{Cr}, \mathrm{Mn}, \mathrm{Mo}, \mathrm{Ni}$ ) as well as $\mathrm{Na}$ and $\mathrm{Zr}$. Fuel weights were obtained by using the results of the cladding composition determinations to calculate the cladding weight and subtract it from the initial sample weight.

Table 12 shows the as-built composition of the fuel pellets for AFC-2C. Recall that the fuel in AFC-2C was MOX and MOX with minor actinides and the oxygen concentrations are not shown. The enrichments are relatively constant and in this case it is more instructive to give the isotopic compositions as percentages of the total fuel weight so as to facilitate depletion calculations. The as-irradiated compositions are shown in Table 13 (actinides) and Table 14 (fission products).

Table 12. AFC-2C As-Built Composition

\begin{tabular}{|c|c|c|c|c|}
\hline \multirow{2}{*}{$\begin{array}{c}\text { Fuel } \\
\text { Component } \\
\text { (wt.\%) }\end{array}$} & \multicolumn{4}{|c|}{ Rodlet } \\
\cline { 2 - 5 } & 2CR2 & 2CR3 & 2CR5 & 2CR6 \\
\hline Total U & 70.6 & 66.6 & 66.6 & 66.6 \\
${ }^{238} \mathrm{U}$ & 29.7 & 29.7 & 29.7 & 29.7 \\
${ }^{235} \mathrm{U}$ & 40.4 & 36.5 & 36.5 & 36.5 \\
\hline${ }^{\mathrm{Total}} \mathrm{Pu}$ & 17.0 & 17.0 & 17.0 & 17.0 \\
${ }^{239} \mathrm{Pu}$ & 16.1 & 16.1 & 16.1 & 16.1 \\
\hline${ }^{237} \mathrm{~Np}$ & & 1.28 & 1.28 & 1.28 \\
\hline${ }^{241} \mathrm{Am}$ & 0.12 & 2.36 & 2.36 & 2.36 \\
\hline
\end{tabular}


Table 13. AFC-2C Postirradiation Composition

\begin{tabular}{|c|r|r|r|r|}
\hline \multirow{2}{*}{$\begin{array}{c}\text { Fuel } \\
\text { Component } \\
\text { (wt.\%) }\end{array}$} & \multicolumn{4}{|c|}{ Rodlet } \\
\cline { 2 - 5 } & $2 \mathrm{CR} 2$ & $2 \mathrm{CR} 3$ & $2 \mathrm{CR} 5$ & $2 \mathrm{CR} 6$ \\
\hline${ }^{234} \mathrm{U}$ & 0.25 & 0.26 & 0.26 & 0.27 \\
${ }^{235} \mathrm{U}$ & 27.20 & 25.92 & 26.83 & 27.56 \\
${ }^{236} \mathrm{U}$ & 1.32 & 1.42 & 1.36 & 1.10 \\
${ }^{238} \mathrm{U}$ & 40.11 & 35.92 & 36.92 & 36.56 \\
$\mathrm{U} \mathrm{Total}$ & 68.87 & 63.60 & 65.38 & 65.35 \\
\hline${ }^{238} \mathrm{Pu}$ & 0.06 & 0.95 & 0.92 & 0.74 \\
${ }^{239} \mathrm{Pu}$ & 13.11 & 12.35 & 13.08 & 13.43 \\
${ }^{240} \mathrm{Pu}$ & 0.96 & 0.97 & 0.99 & 0.95 \\
${ }^{241} \mathrm{Pu}$ & 0.66 & 0.72 & 0.68 & 0.53 \\
${ }^{242} \mathrm{Pu}$ & 0.03 & 0.13 & 0.13 & 0.10 \\
$\mathrm{Pu} \mathrm{Total}$ & 14.81 & 15.15 & 15.79 & 15.76 \\
\hline${ }^{241} \mathrm{Am}$ & 0.14 & 1.39 & 1.53 & 1.70 \\
${ }^{242} \mathrm{Am}$ & 0.01 & 0.12 & 0.12 & 0.11 \\
${ }^{243} \mathrm{Am}$ & 0.01 & 0.04 & 0.04 & 0.03 \\
\hline${ }^{244} \mathrm{Cm}$ & 0.002 & 0.010 & 0.009 & 0.005 \\
${ }^{245} \mathrm{Cm}$ & $<$ & 0.001 & 0.001 & 0.000 \\
${ }^{246} \mathrm{Cm}$ & $<$ & $<$ & $<$ & $<$ \\
${ }^{247} \mathrm{Cm}$ & $<$ & $<$ & $<$ & $<$ \\
${ }^{248} \mathrm{Cm}$ & $<$ & $<$ & $<$ & $<$ \\
\hline${ }^{237} \mathrm{~Np}$ & 0.13 & 1.20 & 1.25 & 1.27 \\
\hline
\end{tabular}


Table 14. AFC-2C Postirradiation Composition (Fission Products)

\begin{tabular}{|c|c|c|c|c|}
\hline \multirow{2}{*}{$\begin{array}{l}\text { Isotope } \\
\text { Content } \\
(\mathrm{wt} \%)\end{array}$} & \multicolumn{4}{|c|}{ Rodlet } \\
\hline & 2CR2 & 2CR3 & 2CR5 & 2CR6 \\
\hline${ }^{85} \mathrm{Rb}$ & 0.010 & 0.011 & 0.009 & 0.010 \\
\hline${ }^{86} \mathrm{Sr}$ & $<$ & $<$ & $<$ & $<$ \\
\hline${ }^{87} \mathrm{Rb}$ & 0.025 & 0.027 & 0.022 & 0.024 \\
\hline${ }^{88} \mathrm{Sr}$ & 0.043 & 0.050 & 0.045 & 0.049 \\
\hline${ }^{89} \mathrm{Y}$ & 0.058 & 0.065 & 0.060 & 0.047 \\
\hline${ }^{93} \mathrm{Zr}$ & 0.089 & 0.100 & 0.092 & 0.071 \\
\hline${ }^{99} \mathrm{Tc}$ & 0.030 & 0.013 & 0.025 & 0.041 \\
\hline${ }^{101} \mathrm{Ru}$ & 0.019 & 0.011 & 0.016 & 0.029 \\
\hline${ }^{102} \mathrm{Ru}$ & 0.019 & 0.009 & 0.017 & 0.028 \\
\hline${ }^{103} \mathrm{Rh}$ & 0.016 & 0.007 & 0.013 & 0.022 \\
\hline${ }^{104} \mathrm{Ru}$ & 0.018 & 0.011 & 0.015 & 0.022 \\
\hline${ }^{105} \mathrm{Pd}$ & 0.028 & 0.033 & 0.023 & 0.026 \\
\hline${ }^{106} \mathrm{Pd}$ & 0.015 & 0.012 & 0.013 & 0.017 \\
\hline${ }^{107} \mathrm{Pd}$ & 0.014 & 0.017 & 0.013 & 0.013 \\
\hline${ }^{108} \mathrm{Pd}$ & 0.010 & 0.012 & 0.008 & 0.009 \\
\hline${ }^{109} \mathrm{Ag}$ & 0.007 & 0.012 & 0.013 & 0.008 \\
\hline${ }^{110} \mathrm{Pd}$ & 0.005 & 0.005 & 0.005 & 0.004 \\
\hline${ }^{111} \mathrm{Cd}$ & 0.002 & 0.001 & 0.002 & 0.002 \\
\hline${ }^{112} \mathrm{Cd}$ & 0.002 & 0.002 & 0.002 & 0.002 \\
\hline${ }^{114} \mathrm{Cd}$ & 0.001 & 0.000 & 0.000 & 0.001 \\
\hline${ }^{116} \mathrm{Cd}$ & 0.001 & 0.002 & 0.001 & 0.002 \\
\hline${ }^{128} \mathrm{Te}$ & 0.035 & 0.028 & 0.032 & 0.027 \\
\hline${ }^{130} \mathrm{Te}$ & 0.120 & 0.089 & 0.106 & 0.089 \\
\hline${ }^{133} \mathrm{Cs}$ & 0.116 & 0.099 & 0.099 & 0.111 \\
\hline${ }^{135} \mathrm{Cs}$ & 0.117 & 0.108 & 0.099 & 0.113 \\
\hline${ }^{136} \mathrm{Ba}$ & $<$ & $<$ & $<$ & 0.002 \\
\hline $137 \mathrm{~m} / \mathrm{Z}$ & 0.118 & 0.117 & 0.100 & 0.110 \\
\hline${ }^{138} \mathrm{Ba}$ & 0.158 & 0.156 & 0.154 & 0.140 \\
\hline${ }^{139} \mathrm{La}$ & 0.161 & 0.180 & 0.167 & 0.129 \\
\hline${ }^{140} \mathrm{Ce}$ & 0.154 & 0.178 & 0.162 & 0.126 \\
\hline${ }^{141} \mathrm{Pr}$ & 0.149 & 0.167 & 0.155 & 0.119 \\
\hline${ }^{142} \mathrm{Ce}$ & 0.144 & 0.160 & 0.149 & 0.115 \\
\hline${ }^{143} \mathrm{Nd}$ & 0.139 & 0.156 & 0.145 & 0.113 \\
\hline $144 \mathrm{~m} / \mathrm{Z}$ & 0.129 & 0.144 & 0.134 & 0.103 \\
\hline${ }^{145} \mathrm{Nd}$ & 0.091 & 0.101 & 0.094 & 0.073 \\
\hline${ }^{146} \mathrm{Nd}$ & 0.079 & 0.090 & 0.083 & 0.063 \\
\hline $147 \mathrm{~m} / \mathrm{z}$ & 0.043 & 0.049 & 0.045 & 0.037 \\
\hline $148 \mathrm{~m} / \mathrm{z}$ & 0.060 & 0.068 & 0.062 & 0.047 \\
\hline${ }^{149} \mathrm{Sm}$ & 0.014 & 0.012 & 0.015 & 0.014 \\
\hline $150 \mathrm{~m} / \mathrm{Z}$ & 0.039 & 0.048 & 0.041 & 0.029 \\
\hline${ }^{152} \mathrm{Sm}$ & 0.011 & 0.013 & 0.012 & 0.009 \\
\hline${ }^{154} \mathrm{Sm}$ & 0.007 & 0.008 & 0.007 & 0.005 \\
\hline
\end{tabular}


Based upon the as-built and post-irradiation values for ${ }^{235} \mathrm{U},{ }^{239} \mathrm{Pu}$ and ${ }^{241} \mathrm{Am}$ the depletion values are shown in Table 15 . Note that the measured depletions for ${ }^{2}{ }^{235} \mathrm{U}+{ }^{239} \mathrm{Pu}$ ' are consistently about twice the as-run prediction. This was because the ${ }^{235} \mathrm{U}$ depletions measured were about twice those predicted. There was variability in the ${ }^{239} \mathrm{Pu}$ depletion (measured vs. predicted) and the predicted numbers were always lower but by a smaller margin than for ${ }^{235} \mathrm{U}$. Note that the ${ }^{235} \mathrm{U}$ variation (measured vs. predicted) for the AFC-2B pins did not follow this pattern.

Table 15. AFC-2C Measured and Calculated (As-run) ${ }^{235} \mathrm{U}+{ }^{239} \mathrm{Pu}$ and ${ }^{241} \mathrm{Am}$ Depletions

\begin{tabular}{|c|c|c|c|c|}
\hline \multirow{2}{*}{ Rodlet } & \multicolumn{2}{|c|}{${ }^{235} \mathrm{U}+{ }^{239} \mathrm{Pu}$ Depletion (at.\%) } & \multicolumn{2}{|c|}{${ }^{241} \mathrm{Am}$ Depletion (at.\%) } \\
\cline { 2 - 5 } & Measured & Predicted & Measured & Predicted \\
\hline 2CR2 & 28.7 & 13.8 & 41.0 & 40.4 \\
\hline 2CR3 & 27.2 & 15.0 & 35.1 & 38.6 \\
\hline 2CR5 & 24.1 & 14.1 & 27.8 & 32.1 \\
\hline 2CR6 & 22.0 & 11.5 & 41.0 & 40.4 \\
\hline
\end{tabular}

\section{SUMMARY}

Baseline PIE has been conducted on transmutation fuel irradiation test AFC-2C. PIE included visual inspection, dimensional inspection, gamma scan, neutron radiography, fission gas analysis, metallography, microhardness testing, and analytical chemistry of the fuel rodlets. Results appear to be within predicted behavior for the AFC-2C MOX fuel rodlets.

\section{REFERENCES}

1 S.L. Hayes, B.A. Hilton, M.K. Meyer, G.S. Chang, F.W. Ingram, S. Pillon, N. Schmidt, L. Leconte, and D. Haas, "U. S. Test Plans for Actinide Transmutation Fuel Development," Trans. American Nuclear Society. Nucl. Soc., 87: 353, American Nuclear Society Winter Meeting, Washington, DC, 17-21 November 2002.

2 B.A. Hilton, D.L. Porter, S.L. Hayes, "AFC-1 Transmutation Fuels Post-Irradiation Hot Cell Examination 4 to 8 at.\% Final Report, Irradiation Experiments AFC-1B, AFC-1G and AFC-1Æ," Idaho National Laboratory, INL/EXT-05-00785, 2005.

3 B.A. Hilton, D.L. Porter, and S.L. Hayes, "Postirradiation Examination of AFCI Metallic Transmutation Fuels at 8 at.\%," Embedded Topical Meeting on Nuclear Fuels and Structural Materials for the Next Generation Nuclear Reactors, Reno, Nevada, 4-8 June 2006.

4 B.A. Hilton, D.L. Porter, and S.L. Hayes, "Postirradiation Examination of AFCI Nitride and Oxide Transmutation Fuels," Embedded Topical Meeting on Nuclear Fuels and Structural Materials for the Next Generation Nuclear Reactors, Reno, Nevada, 4-8 June 2006.

5 H.J.M. Chichester, D.L. Porter, S.L. Hayes, "Postirradiation Examination of AFC-1D, 1G, 1H, and 2A Experiments," Idaho National Laboratory, INL/LTD-11-23242, September 2011.

6 H.J.M. Chichester, "Postirradiation Examination Plan for AFC-2 Metallic and Oxide Fuels," Idaho National Laboratory, PLN-3773, March 2011. 
7 S.L. Hayes, T.A. Hyde, W.J. Carmack, "Irradiation of Metallic Fuels with Rare Earth Additions for Actinide Transmutation in the ATR, Experiment Description for AFC-2A and AFC-2B," Idaho National Laboratory, February 2007.

8 H.J. MacLean, "Irradiation of AFC-2C and -2D Oxide Fuels for Actinide Transmutation in the ATR," Idaho National Laboratory, PLN-2764, August 2008.

9 G.S. Chang, M.A. Lillo, "Cycle 140B Physics Evaluations of AFC-1G, -1H, -2A, and -2B Tests in the East Flux Trap," Idaho National Laboratory, ECAR-97, December 2007.

10 M.A. Lillo, G.S. Chang, "Cycle 141A Physics Evaluations of AFC-1G, -1H, -2A, and -2B Tests in the East Flux Trap," Idaho National Laboratory, ECAR-145, January, 2008.

11 M.A. Lillo, G.S. Chang, "Cycle 142A Physics Evaluations of AFC-1G, -1H, -2A, and -2B Tests in the East Flux Trap," Idaho National Laboratory, ECAR-183, April 2008.

12 M.A. Lillo, G.S. Chang, "Cycle 142B Physics Evaluations of AFC-1H, -2A, and -2B Tests in the East Flux Trap," Idaho National Laboratory, ECAR-299, July 2008.

13 M.A. Lillo, G.S. Chang, "Cycle 143A Physics Evaluations of AFC-2B, -2C, and -2D Tests in the East Flux Trap," Idaho National Laboratory, ECAR-385, 18 September 2008.

14 M.A. Lillo, G.S. Chang, "Cycle 143B Physics Evaluations of AFC-2B, -2C, and -2D Tests in the East Flux Trap," Idaho National Laboratory, ECAR-482, December 2008.

15 J.R. Mitchell, G.S. Chang, "Cycle 144A Physics Evaluations of AFC-2B, -2C, and -2D Tests in the East Flux Trap," Idaho National Laboratory, ECAR-545, February 2009.

16 J.R. Mitchell, G.S. Chang, "Cycle 145A Physics Evaluation of the AFC-2 Experiment in the East Flux Trap," Idaho National Laboratory, ECAR-622, August 2009.

17 J.R. Mitchell, G.S. Chang, "Cycle 145B Physics Evaluation of the AFC-2 Experiment in the East Flux Trap," Idaho National Laboratory, ECAR-825, November 2009.

18 J.R. Mitchell, G.S. Chang, "Cycle 146A Physics Evaluation of the AFC-2 Experiment in the East Flux Trap," Idaho National Laboratory, ECAR-893, February 2010. 